\title{
Wall-resolved Large-Eddy Simulation of a three-element high-lift airfoil
}

\author{
M. Terracol* \\ ONERA, 8 rue des Vertugadins, 92190 Meudon, France. \\ E. Manoha ${ }^{\dagger}$ \\ ONERA, 29 avenue de la Division Leclerc, 92320 Châtillon, France
}

This work deals with a highly-resolved Large-Eddy Simulation of a three-element high-lift airfoil with a deployed slat and flap 7 . The aim of this simulation is two-fold: the first objective is to perform a detailed flow analysis and identify the physical flow mechanisms responsible for noise generation; the second objective is to provide an important numerical database that may be used to assess more affordable numerical approaches based for instance on hybrid RANS/LES methods. The assessment of the present LES relies on an extensive database, collected during a campaign performed in the Onera F2 wind tunnel in the framework of LEISA2, a joint Onera/DLR project. The results of the present LES show an overall agreement with the measurements that is generally within the experimental uncertainty, especially in the slat and flap coves. Differences between the LES and the experiments are present on the flap suction side, where the flow is observed to be very sensitive to slight modifications of the numerical or experimental conditions. The simulation confirms that a large-scale coupled selfsustained oscillations mechanism is present between the slat and flap cavities. Some insight about the transition process on the main wing suction side is also discussed in the paper.

\section{Nomenclature}

$\alpha$

$c$

$C_{P}$

$\delta_{0}$

$\Delta f$

$\Delta t$

Angle of attack, ${ }^{\circ}$

Retracted chord of the airfoil, $m$

Pressure coefficient

Initial vorticity thickness of the shear layer, $\mathrm{m}$

Frequency resolution, $\mathrm{Hz}$

Time-step, s

\footnotetext{
*Doctor, Senior Research Scientist, Department of Aerodynamics, Aeroelasticity and Acoustics, Marc.Terracol@onera.fr

$\dagger$ Doctor, Head of Computational AeroAcoustics Research Unit, Department of Aerodynamics, Aeroelasticity and Acoustics, Eric.Manoha@ onera.fr

$\ddagger$ This study was previously presented as Paper 2014-3050 [1] at the 20th AIAA/CEAS Aeroacoustics Conference, AIAA AVIATION Forum, Atlanta, Georgia, USA, 16 - 20 June 2014 (Terracol, M. and Manoha, E. (2014). "Wall-resolved Large Eddy Simulation of a highlift airfoil: detailed flow analysis and noise generation study").
} 


$\begin{array}{ll}\Delta x^{+}, \Delta y^{+}, \Delta z^{+} & \text {Grid resolution, in wall units in the respective } x, y \text { and } z \text { space directions } \\ f & \text { Frequency, Hz } \\ \lambda_{z} & \text { Spanwise wavelength, } \mathrm{m} \\ L_{z} & \text { Span of the airfoil, } \mathrm{m} \\ M_{\infty} & \text { Free-stream Mach number } \\ v & \text { kinematic viscosity, } \mathrm{m}^{2} / \mathrm{s} \\ \omega_{x} & \text { streamwise vorticity component, } \mathrm{s}^{-1} \\ p & \text { Pressure, Pa } \\ Q & \text { Q criterion, } \mathrm{s}^{-2} \\ \rho & \text { Density, } \mathrm{kg} / \mathrm{m}^{3} \\ R e_{c} & \text { Chord-based Reynolds number } \\ S t & \text { Strouhal number } \\ \tau_{w} & \text { wall shear stress, } \mathrm{kg} / \mathrm{m} / \mathrm{s}^{2} \\ U & \text { Streamwise component of velocity, } \mathrm{m} / \mathrm{s} \\ V & \text { Vertical component of velocity, } \mathrm{m} / \mathrm{s} \\ W & \text { Spanwise component of velocity, } \mathrm{m} / \mathrm{s} \\ u_{\tau} & \text { Friction velocity, } \mathrm{m} / \mathrm{s} \\ U_{\infty} & \text { Free-stream velocity, } \mathrm{m} / \mathrm{s} \\ x, y, z & \text { Spatial coordinates, } \mathrm{m}\end{array}$

\section{Introduction}

IGH lift devices deployed on transport aircraft to increase lift at low speed significantly contribute to airframe
noise generated by these aircraft during approach and landing operations [2]. The unsteady flows around the leading edge slat and the trailing edge flap are very complex. So is the physics of the involved noise sources induced by these turbulent flows.

Designing silent -or less noisy- high-lift devices assumes understanding the physics of these aeroacoustic mechanisms. For this purpose, modern numerical methods for the simulation of unsteady flows and far-field noise are more and more useful. However, further development of these methods is limited by the general lack of reliable experimental data, including local aerodynamic and far-field noise measurements. Among several reasons explaining the rarity of such data, the most meaningful is probably the difficulty to gather reliable aerodynamic and acoustic data in a wind tunnel with a high lift model. Closed-section wind tunnels are indeed adapted to aerodynamic measurements but 
generally provide acoustic data with poor quality, whereas open-jet acoustic facilities are suited for far-field noise measurements. Nevertheless, the lift of the model induces significant deviation of the wind tunnel main stream, yielding a large distortion of the flow around the model.

High-lift noise has also been studied intensively using unsteady numerical simulations, generally based on zonal hybrid RANS/LES approaches [3-5], global hybrid RANS/LES methods [6-17], wall-modeled LES [18] or LBM-VLES [19, 20]. These works have provided significant progress in the understanding of high-lift wing noise, but suffer from a lack of available experimental data for a full assessment. In these simulations, most of the computational effort is usually focused on the slat area, since it represents one of the major contributors to the radiated noise [2] of high-lift airfoils. However, Deck and Laraufie [6] pointed out a possible acoustic coupling between the slat and flap coves. This would require an additional computational effort to properly account for the flap region unsteadiness. This point will also be addressed in the following study.

In the present paper, we present a highly-resolved compressible LES of the flow over a full high-lift airfoil with a deployed slat and flap. The results of this simulation are compared to measurements coming from a highly detailed aerodynamic/acoustic experiment. This test was performed in a closed-section wind tunnel using the same two-dimensional airfoil at identical scale [21]. The Reynolds number for both experimental/numerical approaches, based on the airfoil retracted chord $(c=0.3 \mathrm{~m})$ is 1.23 million. To the author's knowledge, this simulation represents the first wall-resolved LES of a three-element high-lift airfoil, resolving all the physical phenomena involved in the flow dynamics.

The configuration of interest has been extensively studied experimentally in the framework of the joint Onera/DLR project LEISA2 [21], with the objective to build an experimental aerodynamic and acoustic database for a twodimensional high lift airfoil equipped with a leading edge slat and a trailing edge flap. This data set is available to the aeroacoustic community to assess and validate advanced CFD/CAA methods for the prediction of unsteady flow and radiated noise. The LEISA2 project was co-founded and coordinated by Onera and DLR, the French and German Aerospace Research Centers. DLR provided its "F16" high lift airfoil model, conducted acoustic tests in its AWB acoustic wind tunnel, and designed and manufactured the necessary parts to adapt the model to Onera's F2 wind tunnel. Onera conducted aerodynamic and acoustic tests with this model in F2. The database is co-owned by Onera and DLR and made public in the framework of the Benchmark for Airframe Noise Computation [22] (BANC). It aims to promote the development of CFD/CAA techniques by allowing comparisons of simulations achieved by any interested contributors. A first experimental campaign was performed in Onera's F2 closed wind tunnel facility and was dedicated to the characterization of the unsteady aerodynamic flow over the airfoil. The retained experimental approach makes use of up-to-date aerodynamic measurement techniques based on optical devices such as 2D PIV and steady/unsteady 2D LDV, combined with hot-wire probe for instantaneous 2-point velocity measurements. The model was also equipped with static pressure probes and unsteady pressure transducers. Moreover, acoustic measurements were 
obtained with a wall array of 120 microphones mounted on the model pressure side. A second experimental campaign was dedicated to farfield acoustic measurements and was performed in the DLR AWB open-jet facility (Acoustic Wind tunnel Braunschweig).

The present LES aims to provide a well-documented numerical database in addition to the experimental LEISA2 database, obtained in ideally "clean" numerical conditions (i.e. no installation effects or free-stream turbulence). Such a database is therefore expected to be of great help for flow physics understanding, as well as a valuable validation tool for more affordable numerical approaches based on wall-modeled LES or hybrid RANS/LES methods.

The simulation presented in this paper is based on a very fine resolution of the wall region and a significant spanwise extent of the computational domain equal to two slat chords. The numerical method is based on the LES approach, with a direct resolution of the near-wall flow dynamics. The computation simulated about 70 ms of physical time, with 40 ms available for data sampling.

The paper is organized as follows: First, Section $\Pi$ describes the configuration of interest. Then, the numerical approach used for the study is detailed in Section III. Finally, the obtained results are presented and discussed in Section IV

\section{Configuration}

The configuration retained for the study is the three-element wing airfoil with a deployed slat and flap (released as FNG by Airbus) that has been investigated in the former DLR/Onera project LEISA. This airfoil has been widely used by DLR [23] and several models were built at various scales. This airfoil has been used in recent European projects devoted to noise and turbulent flow predictions such as ATAAC (Advanced Turbulence simulation for Aerodynamic Application Challenges), VALIANT (VALidation and Improvement of Airframe Noise prediction Tools), or more recently in the H2020 project ARTEM (Aircraft noise Reduction Technologies and related Environmental iMpact). It is also released as a test case in the Benchmark for Airframe Noise Computation [22] (BANC, Category 6) organized by NASA LaRC and sponsored by AIAA.

In the framework of these projects, several unsteady simulations based mainly on hybrid RANS/LES techniques have been performed on this geometry (see for instance [3, 17, 24, 26]).

The smaller-scale airfoil considered in this study is called F16 and was formally built for DLR's AWB aeroacoustic wind tunnel. Its retracted chord is $0.3 \mathrm{~m}$. The unswept three-element reference configuration of this F16 geometry corresponds to the slat and flap deployed at 27.834 and 35.011 degrees respectively. Figure 1 displays a section of the airfoil.

The free-stream flow conditions are the following:

1) Flow Mach number $M_{\infty}=0.178$ i.e. inflow velocity $U_{\infty}=61.5 \mathrm{~m} / \mathrm{s}$.

2) Retracted chord of the airfoil $c=0.3 \mathrm{~m}$. 
3) Angle of attack $\alpha=6.15^{\circ}$.

The associated chord-based Reynolds number of the problem is $R e_{c} \simeq 1,230,000$.

An important experimental campaign has been performed jointly by Onera and DLR in a project named LEISA2 [21], using ONERA's F2 aerodynamic wind tunnel. This facility is dedicated to intensive aerodynamic measurements using optical devices such as PIV and LDV. It is characterized by a very low level of inner turbulence: the measured free-stream velocity fluctuations represent about $0.04 \%$ of the inflow velocity. During these tests, many steady and unsteady data have been collected, using several techniques based on steady/unsteady LDV, PIV, hot wires, and on-board wall unsteady pressure sensors and static pressure taps. To illustrate this point, Figure 2 presents the PIV test set-up and a resulting 2D PIV map composed of several individual PIV maps necessary to cover the mean flow. To account for possible blockage effects of the closed-wall wind tunnel, a preliminary angle-of-attack adjustement was performed before the unsteady measurements. This adjustement aimed at matching the $C_{P}$ distributions predicted by 2D RANS simulations at $\alpha=6.15^{\circ}$. Consequently, two actual angles of attack of $6.1^{\circ}$ and $6.5^{\circ}$ were retained in the experiments, depending on whether the airfoil was placed respectively in "up' ${ }^{*}$ or "down'f position. Indeed, the position of the airfoil had to be changed during the tests, to allow for the best possible optical access on both of its sides.

Other test were performed in DLR's AWB open-jet wind tunnel, dedicated to aero-acoustics measurements. Due to the open jet configuration, the angle-of-attack was tuned to $\alpha=14.5^{\circ}$ in these experiments, in order to match the $C_{P}$ distribution in the slat area from closed wind tunnel experiments at $\alpha=6^{\circ}$. This mandatory tuning of the angle of attack is due to the fact that high-lift airfoils usually generate a significant flow deflection in open-jet facilities, where the flow out of the jet is almost at rest. As a consequence, large angle-of-attack corrections have to be performed in these experiments. Nonetheless, the AWB tests provided valuable far-field acoustic measurements and source localization.

The experimental methodology and results are fully detailed in the paper by Manoha and Pott-Pollenske [21].

In the present study, we will mainly focus on the aerodynamic predictions around the airfoil. Free-field flow conditions have been applied in the computations, since they are closer to the closed wind-tunnel conditions, from an aerodynamic point of view. These conditions are also the most commonly used ones for aerodynamic numerical simulations around airfoils, although accounting for the wind tunnel walls should certainly be of significant interest for future works.

\section{Numerical approach}

\section{A. Numerical method}

All the computations presented in this study have been performed using ONERA's in-house research CFD/CAA code FUNk. This solver solves the compressible Navier-Stokes equations on structured multi-block grids, either in DNS,

\footnotetext{
*Pressure side oriented towards the floor

${ }^{\dagger}$ Pressure side oriented towards the ceiling
} 
LES, RANS or hybrid RANS/LES modes. Great care has been taken to ensure a very good efficiency of the solver on massively parallel supercomputers.

A two-dimensional steady RANS simulation has first been performed to initialize the LES. It has been carried out using the Spalart-Allmaras turbulence model [27]; Roe's scheme has been used for spatial discretization while time integration has been performed using an implicit local time-stepping approach.

Starting from the obtained steady RANS solution, the LES simulation has then been carried out. The subgrid model used is the selective mixed-scale model [28, 29]. This model introduces a subgrid viscosity, as:

$$
\mu_{s g s}=\bar{\rho} C_{m} f_{s}(\theta) \Delta^{3 / 2} q_{s g s}^{1 / 4}|\tilde{S}|,
$$

where $C_{m}=0.06, \bar{\rho}$ is the filtered density, $\Delta$ is the subgrid length scale, $q_{s g s}$ is an estimate of the subgrid kinetic energy, $\tilde{S}$ is the filtered strain-rate tensor and $f_{s}(\theta)$ is the selective function. This function is dependent upon the angle $\theta$ between the instantenous vorticy vector and a test-filtered vorticity vector. It activates the subgrid viscosity only in flow regions where intermittency is detected. Full details about this model can be found in [28, 29].

The spatial discretization used for the LES is the modified [30] AUSM+(P) scheme. This method minimizes the numerical dissipation by introducing a wiggle detector to reduce the application of numerical stabilization. Time integration has been performed using the second-order implicit backward-Euler scheme with a time step $\Delta t=2 \cdot 10^{-7} \mathrm{~s}$. This value actually corresponds to advective CFL numbers $\left(C F L_{a d v}=\frac{|U| \Delta t}{\min \left(\Delta x_{i}\right)}\right)$ of about unity in the most constrained regions near the wall. It is worth noting that the time step expressed in wall units $\Delta t^{+}=\Delta t u_{\tau}^{2} / v$ presents a mean value of about 0.25 in the attached turbulent boundary layers. This perfectly fits the recommended value $\left(\Delta t^{+}<0.4\right)$ proposed by Choi and Moin [31] for the DNS of wall-bounded flows. Each time iteration involves the resolution of a non-linear system by mean of a Newton approach. In our case, 15 sub-iterations per time step have been found sufficient to get a satisfactory convergence of the Newton method, with a reduction of the residuals by at least one order of magnitude for all the conservative variables. Such a reduction is sufficient to yield good results in LES of wall-bounded flows, as shown in [32].

The LES simulation has been performed on 4096 cores of the CINES supercomputer Jade with an average CPU performance of $0.89 \mu s$ per point and sub-iteration.

\section{B. Computational grid}

A highly-resolved structured multi-block grid has been designed for the study. The computational domain extends to 50 chords away from the airfoil in the horizontal and vertical directions. A no-slip wall boundary condition is applied on the slat, wing and flap surfaces, while a classical in/out characteristic boundary condition is adopted in far-field. Periodicity boundary conditions are applied in the spanwise direction. To that end, the spanwise extent retained for the 
study has been chosen large enough to allow for a full spanwise decorrelation of the flow all along the airfoil. It has been set to one quarter of the airfoil chord, i.e. $L_{z}=0.075 \mathrm{~m}$. This spanwise extent represents approximately two slat chords (the recommended span in the slat region being of about 0.8-1 slat chord [3, 12]) and one flap chord which might be sufficient, even in the presence of a large separation on the flap surface.

The grid resolution has been carefully tuned to guarantee an accurate resolution of the shear layers and turbulent boundary layers. More particularly, the near-wall grid requires a significant resolution, since the near-wall energycontaining eddies have to be explicitly resolved. The grid resolution required in this area is therefore very fine. This is not the case in hybrid RANS/LES computations performed on such configurations, where the near-wall turbulence is modeled. A full resolution of turbulent boundary layers by a DNS approach [33] requires grid resolutions as fine as $\Delta x^{+} \simeq 6, \Delta y_{\text {wall }}^{+} \simeq 0.3$ and $\Delta z^{+} \simeq 4$, where the superscript "+" stands for wall units. In the present case, such a fine grid resolution applied on the overall configuration remains out-of-reach of our computing capabilities. This is why the LES approach is considered in this study. The respective resolutions used in the streamwise, wall-normal and spanwise directions are: $\Delta x^{+} \simeq 30-40, \Delta y_{\text {wall }}^{+} \simeq 1$ and $\Delta z^{+} \simeq 10$. Although finer grid resolutions or higher-order schemes [34] are considered by some authors for wall-resolved LES, the present resolution was shown to yield good predictions of a transitional separation bubble and turbulent boundary layer development on a flat plate [35], using the same solver and numerical method. It is also worth noting that the reduction of the errors by grid refinement is non-monotonous in wall-resolved LES, as evidenced in [36] and [37]. The grid resolution adopted for the present LES was shown to yield acceptable error levels in these studies, although the combined choice of numerical method, grid resolution and subgrid model is expected to influence the results. As a consequence, there exists no universal rule for the mandatory grid resolution in LES where the near-wall production events are resolved. As stated before, the present combination of numerical scheme and grid resolution was shown to be well suited for the LES of wall-bounded flows.

Great care was also taken to ensure a proper resolution of the initial shear-layer development at the slat cusp and slat trailing-edge. The slat cusp and trailing edge are blunt, with respective thicknesses $h_{\text {cusp }}=0.28 \mathrm{~mm}$ and $h_{T E}=0.26 \mathrm{~mm}$. Due to the presence of blunt trailing-edges, the classical expression of the shear layer vorticity thickness cannot be adopted. Therefore, we introduce here two alternative definitions of the initial shear layer thickness:

$$
\begin{aligned}
& \delta_{S L}=h+\delta_{\text {up }}+\delta_{\text {low }} \\
& \delta_{S L}^{\star}=h+\delta_{\text {up }}^{\star}+\delta_{\text {low }}^{\star},
\end{aligned}
$$

where $\delta_{u p}$ and $\delta_{\text {low }}$ denote respectively the boundary layer thicknesses on the upper and lower sides of the cusp/trailingedge. The second expression $\delta_{S L}^{\star}$ is based on the corresponding displacement thicknesses $\delta_{\text {up }}^{\star}$ and $\delta_{\text {low }}^{\star}$. Table 1 summarizes the number of grid points used to discretize the blunt trailing edges and shear layer thicknesses. It is worth noting that that the initial shear layer thicknesses are finely discretized in the simulation, by up to 62 points at the cusp 
when using the $\delta_{S L}$ definition.

\begin{tabular}{|l|ccc|}
\hline & $h$ & $\delta_{S L}^{\star}$ & $\delta_{S L}$ \\
\hline Slat cusp & 38 & 48 & 62 \\
Slat trailing-edge & 15 & 26 & 44 \\
\hline
\end{tabular}

Table 1 Number of grid points used for the discretization of the initial slat cusp and trailing-edge shear layers.

The wall-normal grid resolution has also been tuned in order to correctly resolve acoustic waves up to $20 \mathrm{kHz}$ with a minimal spatial resolution of 16 points per wavelength (which is compatible with the chosen numerical scheme), up to a distance of about $20 \%$ of the airfoil chord.

The corresponding two-dimensional grid in the $x-y$ frame is composed of about 1.27 million cells and has been extruded on 2048 planes in the spanwise ( $z$ ) direction to cover the targeted span of $L_{z}=c / 4$ with the desired $\Delta z^{+} \leq 10$ resolution. The resulting computational grid is composed of about 2.6 billion cells, distributed on 10,688 blocks and 4096 cores (Nehalem $2.8 \mathrm{GHz}$ ) for the computation. This simulation has been performed using the HPC resources of CINES under the allocation c20132a7049 made by GENCI (Grand Equipement National de Calcul Intensif), for a total CPU time of about 6 millions of hours.

\section{Results}

Starting from the steady RANS solution, the computation has been performed during a transient physical integration time of $\mathrm{T}=30 \mathrm{~ms}$ (representing about 6 characteristic times $c / U_{\infty}$ ). After this, statistics and unsteady data at selected numerical probes have been gathered during $40 \mathrm{~m}$ : Statistical convergence of the simulation was carefully monitored by checking the statistics after each computational run (of about $2 \mathrm{~ms}$ ), as well as unsteady signals of the velocity and pressure at several numerical probes located in the field.

The next sub-sections present the results that have been obtained, including a description of the physical phenomena involved in the flow and a comparison with experimental data [21].

\section{A. Instantaneous flow}

Because of the large amount of numerical data available, only flow visualizations limited to restricted flow areas have been possible. Four selected volumes have been extracted for 3D flow visualizations (see Figure 3, as well as the mid-span plane for 2D snapshots.

Figure 4 presents numerical Schlieren views of the flow in the mid-span plane. Several flow features can be observed on this figure:

\footnotetext{
$\doteqdot$ In addition to these data, sampling was also carried out on a surface surrounding the airfoil and on its surface, in order to perform far-field noise predictions using integral methods. Due to technical constraints, the simulated physical time was too short to allow for reliable far-field predictions and comparison with the AWB measurements.
} 
1) A large recirculation bubble is present in the slat cove. This large bubble is bounded by a turbulent shear layer which originates from the slat cusp.

2) This shear layer is convected inside the slat cove and eventually impinges on the upper slat surface.

3) A turbulent wake is generated at the slat trailing-edge. This wake is observed to interact with turbulent structures coming from the slat cove shear layer.

4) The vortex shedding at the trailing edge appears to be a significant noise source since acoustic waves propagating upstream and originating from the trailing edge are clearly observed in Figure4(left view).

5) At about $x / c=0.2$, transition to turbulence is observed in the boundary layer at the suction side of the main wing element. This point will be addressed in Section IV.D.

6) A turbulent boundary layer develops on the suction side of the main wing element and is finally diffused at its trailing-edge; it is interesting to see that the slat wake survives up to the flap region and remains well resolved in the simulation, without noticeable dissipation.

7) A turbulent wake is generated at the trailing edge of the main wing element and interacts with the boundary layer on the flap.

8) Transition of the boundary layer is observed on the flap suction side, at about $x / c=0.98$. It is to be noted that no flow separation on the flap is observed in the simulation. This point will be discussed later on in the paper.

9) A turbulent wake is generated at the flap trailing-edge.

10) The flow inside the flap cove presents physical features very similar to those observed in the slat cove, with a large recirculation bubble bounded by a turbulent shear layer.

The flow inside the slat cove can be observed in more detail by looking at Figure 5 (left picture). It is noticeable that the shear layer becomes almost immediately turbulent and fully three-dimensional, even very close to the slat cusp. Previous work performed on a similar geometry [3, 6, 26] using highly-resolved RANS/LES methods highlighted the presence of 2D Kelvin-Helmholtz structures in the shear layer near the slat cusp, that are not present in this simulation. This might be due to the finer grid resolution adopted in the present simulation: In Reference [3], 15 points were used in the initial shear layer vorticity thickness. In References [6] and [26], 25 points were used. The grid resolution used in the present study is indeed much finer, with 62 points located in the initial slat cusp shear layer thickness. Another important point is the spanwise grid resolution: a step of $\Delta z / c=1 \times 10^{-3}$ was used in [3] and $\Delta z / c=1.25 \times 10^{-3}$ in [6] and [26]. The present grid resolution is $\Delta z / c=1.22 \times 10^{-4}$, i.e. more than 8 times finer. All these differences in grid resolution certainly promote the growth of small scales and three-dimensional instabilities in the LES, compared to previous RANS/LES computations. Another point is that in the present geometry, the slat cusp - sharp in previous works - presents a blunt trailing-edge. This locally modifies the flow dynamics in that region, by introducing a small recirculation area. As a consequence, the local shear velocity is increased, which contributes to a faster transition to turbulence. 
As described in previous works, the shear layer is then accelerated in the slat cove and impinges on the pressure side. This may represent an important noise source, as well as a possible contributor to an acoustic feedback loop phenomenon in the slat cove [3]. At the impingement location, on the one hand, part of the turbulent structures are re-ingested inside the slat cove and interact with the shear layer at the slat cusp. On the other hand, large packets of turbulent structures present in the shear layer are converted to elongated streamwise-oriented vortices, convected and accelerated downstream of the slat. These structures are observed to interact with the slat trailing edge and the turbulent wake generated at this location.

As mentioned previously, the flow dynamics in the flap cove is very similar to the one observed in the slat cove (see Figure 5 right picture). A slight difference is observed in the shear layer dynamics in its early stage, where more two-dimensional coherent structures are observed, as in the presence of a sharp cusp geometry. In that case, the shear layer appears to be more receptive to the natural Kelvin-Helmholtz instability.

Figure 6(left) focuses on the boundary layer transition on the main wing suction side. It appears that the slat wake may be a major contributor to the onset of transition in the main wing boundary layer. Indeed, transition seems to occur when the slat wake penetrates the boundary layer and most probably generates significant near-wall fluctuations. As it will be detailed later on in the paper, the transition process actually results from a combination of two distinct phenomena. The first one is due to the presence of localized separated areas triggered by a local change of curvature of the airfoil surface. The second one is a bypass transition triggered by the slat wake. These two transition mechanisms are addressed in more detail in Section IV.D. Downstream of the transition area, the boundary layer develops along the airfoil and finally reaches the trailing edge as a typical turbulent boundary layer (see Figure 6, right).

Finally, Figure 7 presents an overall view of the dilatation field in the mid-span plane. One can identify on this figure the main physical phenomena involved in the generation of acoustic waves, as well as acoustic propagation in the near field. As expected, the acoustic waves appear to be attenuated 0.2 chords away from the airfoil, under the combined action of the grid stretching and the numerical scheme's intrinsic dissipation. On this figure, it quite clearly appears that the slat cove region is the main contributor to the radiated noise. However, acoustic waves originating from the flap region are also observed, although with a lower intensity.

\section{B. Steady flow analysis}

Figure 8 presents the mean wall-pressure coefficient distribution, obtained from the LES and steady RANS computations, compared to the measurements. While the RANS simulation leads to a very good agreement with the experiment, the LES result leads to higher magnitudes of the peaks on the suction side of the airfoi $\$$ Unfortunately, no experimental data are available near the leading edge of the main wing, where the main suction peak is observed. Indeed, in this area, only unsteady pressure fluctuations were measured during the wind tunnel tests.

\footnotetext{
${ }^{\S}$ The predicted $C_{\boldsymbol{P}}$ distribution actually agrees better with the measurements at higher angles of attack, not included here for the sake of clarity.
} 
Looking more closely at the $C_{P}$ distributions near the flap trailing-edge, noticeable differences are observed in that area between the LES and the experiment. More particularly, as it will be discussed later on, a flow separation on the flap suction side might be present in some cases in the wind tunnel experiments, but is not predicted by the LES computation. This point might be an explanation for the higher lift predicted by the LES, since flap separation modifies the overall circulation around the airfoil.

Figure 9 presents a comparison of the LES mean flow against PIV measurements. The mean flow acceleration predicted by the LES is a bit more pronounced on the suction side. This is consistent with the higher magnitudes of the suction peaks of the pressure coefficient with respect to the measurements. In the slat cove region, a very good agreement is observed; more particularly, the size and shape of the mean recirculation bubble appear to be almost perfectly reproduced by the simulation: the main bubble axis (red dotted line in fig. 9), as well as the locations of the vortex core and reattachment point are very accurately predicted. Moreover, it is striking that the bubble exhibits an elongated egg-shape that is hardly reproduced by RANS simulations, which usually predict a rounder shape of the bubble.

The agreement with the experiment is however less satisfactory in the flap cove region where differences of the main shape of the recirculation bubble are observed. They can probably be explained by significant deviations observed on the flap suction side: in that area, a massive flow separation is observed in the PIV measurements, but is not predicted by the LES. However, it must be pointed out that the presence of this separation was not observed systematically during the measurements; it appeared to be highly dependent on the experimental run. For instance, the experimental pressure coefficient distribution presented in Figure 8 is not consistent with such a massive separated area. As it will be detailed later on, such a massive separation is also not highlighted by the LDV measurements. Its presence in the PIV measurements therefore remains unfortunately not fully explained. The possible intermittency of the flap separation phenomenon on high-lift airfoils has been previously observed and discussed by several authors. For instance, Deck [7] reports several experimental and numerical works where two different states of the flow on the flap were observed, depending on tiny modifications of the experimental (e.g. surface coating of the airfoil to avoid optical reflections) or numerical conditions (e.g. initial conditions). In the present study, it was indeed observed during preliminary 2D RANS calculations that the occurrence or not of flow separation on the flap is highly dependent on the numerical scheme used, which supports the previous discussion. An additional 2D steady RANS simulation has been performed afterwards to investigate the possible blockage effect due to the wind tunnel floor and ceiling on the flow dynamics on the flap. This additional simulation was performed exactly at the same angle of attack $\left(\alpha=6.15^{\circ}\right)$. Figure 10 presents a comparison of the flow predicted on the flap by the free-field RANS computation and the one predicted by this new simulation, including the wind tunnel floor and ceiling. It appears that the presence of these walls induces a separation on the flap, which is not observed in the free-field calculation. The distributions of the pressure coefficient predicted by the two RANS computations are very close, except on the flap suction side, where a plateau distribution is observed near 
the trailing edge, due to flow separation. From a general point of view, both numerical and experimental tests seem to highlight a great sensitivity of flow separation on the flap to external effects and perturbations. This point should therefore deserve careful attention in future studies.

Figure 11 presents the resolved RMS pressure distribution computed from the LES. Several flow regions are associated to significant levels of pressure fluctuations and may act as acoustic sources. However, it is noticeable that the slat region appears as the main acoustic source. Indeed, the signature of acoustic radiation is visible in the $p_{R M S}^{\prime}$ distribution around the slat, where a dipolar pattern is observed, up to a distance of $0.2 c$ from the airfoil.

Figure 12 presents the resolved RMS wall-pressure coefficient distribution for the three elements of the wing. The $C_{P}^{\prime}$ distribution on the slat exhibits two main peaks. The first one is located at about $x / c=0.375$ corresponding to the impingement of the slat shear layer on its internal upper surface. It is noticeable that this peak is distributed over quite a large area, which can be explained by the unsteady flapping of the shear layer. The second peak located at the slat trailing edge presents a higher intensity. It is associated to the turbulent wake generated at the trailing-edge, and to the diffraction of turbulent structures coming from the slat cove at the trailing-edge. This phenomenon appears as one of the main noise sources present in the flow. A strong peak of $C_{P}^{\prime}$ is also observed at the suction side of the main wing element, at about $x / c=0.2$. This peak is clearly associated to the transition process occurring in the boundary layer, possibly due to a receptivity mechanism of the boundary layer to the slat wake perturbations, as depicted in Figure 6 Finally an important peak is also present on the flap suction side at about $x / c=0.98$. It also corresponds to a boundary layer transition process occurring at this exact location, as discussed in section IV.A

Flow statistics have been extracted from the numerical results (LES and RANS) along several rakes, chosen to fit selected LDV2D measurement locations. Figure 13 displays the rakes that have been retained for the following results analysis. Several rakes are located inside the slat cove, inside the flap cove, on the suction and pressure side of the main wing element and on the flap suction side. It is to be noted that the name retained here for each rake has been derived directly from the name of its corresponding experimental data set, by simply keeping the main last digits, e.g. rake 04-2 of Figure 13 corresponds to the data set 11104-2 of the experimental campaign. PIV results have also been extracted along each of these rakes to allow for additional comparisons to be made.

Figure 14 compares the numerical results obtained by LES and RANS with steady LDV and PIV measurements along four rakes located in the slat main shear layer (rakes 04-2, 04-4, 04-6 and 04-8 in Figure 13. The two-dimensional resolved turbulent kinetic energy in these plots is defined as:

$$
k_{2 D}=\frac{1}{2}\left(U_{R M S}^{\prime 2}+V_{R M S}^{\prime 2}\right)
$$

where $U_{R M S}^{\prime}$ and $V_{R M S}^{\prime}$ are the resolved RMS velocity fluctuations in the respective $x$ and $y$ directions. First of all it is to be noted that, the RMS velocity fluctuations obtained by PIV appear to be of a significantly lower magnitude than 
those measured using LDV. This can most probably be explained by the very different time sampling frequencies of these two approaches. The LDV is acquired at a mean frequency of about $20 \mathrm{kHz}$, while the PIV has about $5 \mathrm{~Hz}$ of frequency resolution, which certainly filters out a significant amount of turbulent fluctuations. The agreement between the LES results and the LDV measurements is satisfactory, for both the mean and RMS velocity components, except at the very beginning of the shear layer where the RMS velocity fluctuations predicted by LES are of lower magnitude. This is possibly due to the residual free-stream turbulence present in the wind tunnel tests (not accounted for in the simulation) which fastens the transition process of the shear layer. An excellent agreement is then observed in the fully-developed shear layer, especially for the RMS quantities, although a general under-estimation of the maximal predicted mean velocity is observed. Moreover, we can note that the RANS calculation is unable to predict correctly the shear layer development, whereas the LES provides a very good prediction of the mean shear layer properties (thickness and position), even close from the cusp.

Figure 15 presents the same kind of comparisons for the four rakes located in the flap cove (rakes 18-1, 18-3, 18-5 and 18-7 in Figure 13. The agreement between the LES and the LDV measurements appears to be almost perfect for the mean flow velocity profiles, at each station located in the flap cove. Slight differences between the PIV and LDV measurements are observed on the mean flow. These differences may be due to a different state of the flow on the suction side of the flap, since no separation appeared to be present during the LDV measurements (see the following discussion and Figure 18]. Again, the shear layer characteristics predicted by LES are in a much better agreement with the experiment than those predicted by RANS. At the very beginning of the flap cove shear layer (station 18-1), the turbulent fluctuations predicted by LES are again of lower magnitude than the ones measured by LDV, but the agreement then becomes quite good for downstream stations. As for the slat cove shear layer, this might be due to a slightly faster transition of the shear layer in the experiment, probably explained by the presence of a residual turbulence level in free field in the experiment, not accounted for in the LES. This point is confirmed by looking at Figure 16 presenting the flow statistics along the rake 09-1 located at the pressure side of the main wing element, just upstream of the flap cove. There, the LES predicts a purely laminar boundary layer, while a small level of velocity fluctuations is measured in the experiment, although not exceeding $2 \%$ of the free-stream velocity.

Figure 17 presents the flow statistics on the suction side of the main wing element (rakes 32-2, 33-4, 33-5 and 35-6 in Figure 13]. At the three stations 32-2, 33-4, 33-5, located in the slat wake, the mean velocity magnitude profiles predicted by the simulations are in quite good agreement with the measurements. As already mentioned, the velocity magnitude is slightly higher in the LES, but the general shape of the velocity profile is very well reproduced, as well as the location of the wake (small velocity deficit). At station 32-2, located just downstream of the slat trailing edge, the RMS velocity fluctuations are in quite good agreement with the measurements, except the streamwise component, which is a bit over-estimated. Further downstream, the RMS velocity fluctuations magnitudes are significantly lower in the LES than in the LDV measurements. Near the main wing trailing edge, typical turbulent boundary layer profiles are 
observed, for both the mean velocity and turbulent fluctuations. Here, the agreement between the simulation and the measurements (both LDV and PIV) is rather good.

Finally, Figure 18 shows the flow statistics at several stations on the suction side of the flap and in its close wake (rakes 35-7, 35-8, 35-9 and 35-10 in Figure 13). On these plots, $U_{s}$ represents the mean velocity magnitude in the $x-y$ plane, signed by the streamwise velocity component i.e. $U_{s}=\sqrt{U^{2}+V^{2}} \times \operatorname{sign}(U)$. Negative values of $U_{s}$ therefore reveal the presence of mean flow separation. As already discussed, quite a large variability of the results is observed on the flap surface, with very different results occurring between the LDV and PIV results. The general trend is that the LES tends to provide some profiles closer from the LDV measurements, with no flow separation on the flap. However, the turbulent fluctuations appear to be of a significantly lower magnitude in the LES, except at the first station 35-7 located directly in the wake of the main wing element.

Two-point spanwise correlations have also been computed using unsteady sampling at several probes displayed in Figure 19. Each of the probes shown on this picture actually consists of a rake of 32 equally-spaced points in span in the simulation and corresponds to an experimental point where unsteady LDV measurements have been performed. These probes will therefore also be used for the spectral analysis presented in the next section.

The analysis of the two-point spanwise correlation coefficients presented in Figure 20 shows that a full spanwise de-correlation of the flow quantities is obtained in the slat cove, with a very fast decrease of the spanwise correlation of velocity along the span. Looking at the two-point spanwise correlation at several points from the slat shear layer, it appears that (when using periodicity boundary conditions in span), a spanwise extent of about 0.8-1 slat chord is sufficient to get an appropriate representation of the slat cove flow dynamics. This is in good agreement with previous findings by Lockard and Choudhari [12] and Terracol et al. [3].

The same conclusion holds in the flap cove area. There, a spanwise extent of about 0.8 chords of the flap cove appears sufficient to provide a reliable representation of the flap cove flow dynamics.

\section{Spectral analysis}

Using some of the sampling probes displayed in Figure 19, velocity and pressure spectra have been computed from the LES. All the spectra presented in the following have been obtained using a total sampling time of $40 \mathrm{~ms}$. Pressure spectra have been computed using a frequency resolution of $100 \mathrm{~Hz}$, whereas velocity spectra, which are usually more focused on the high frequency information, used a frequency resolution of $150 \mathrm{~Hz}$ to increase spectral averaging. Each spanwise point provided its own spectrum so that an additional spanwise averaging of the spectra could also be performed for increased smoothing.

The velocity spectra obtained in the shear layer of the slat cove are displayed in Figure 21 They are compared to the experimental spectra obtained by unsteady LDV. Close to the slat cusp (probe 05-2), the overall magnitude of the velocity fluctuations appears to be significantly lower in the LES than in the LDV measurement. As already stated in the previous 
sections, this discrepancy may certainly be due to residual free-stream turbulence in the experiment, which triggers a faster transition of the shear layer. Advancing downstream in the shear layer, a transition to fully-developed turbulence is observed and the agreement between the LES and the experiment becomes better. Close to the impingement location of the shear layer on the upper surface of the slat (probes 08-8 and 08-15), a broadband peak around $3 \mathrm{kHz}$ appears on the PSD of the streamwise velocity component, that could be the trace of an horizontal flapping of the shear layer. This peak appears to be well reproduced by the simulation. In the shear layer, the turbulence appears to be homogeneous and isotropic, i.e. the PSD of both the streamwise and vertical components of velocity follow a $-5 / 3$ power law. Near the slat trailing-edge, the streamwise velocity spectrum follows a -1 power law, as observed in the near-wall region of turbulent boundary layers. This is also an indication of the conversion of the flow structures in elongated streamwise-oriented vortices, as already stated in section IV.A.

Figure 22 presents the velocity spectra obtained in the shear layer of the flap cove, at points 19-1, 19-2, 19-3 and 19-4 of Figure 19 In the early stages of the shear layer, the spectra appear to be dominated by one main broadband peak, at about $3 \mathrm{kHz}$ in the LDV measurements. This peak is also present in the LES results, at a frequency of about $3.6 \mathrm{kHz}$. It is identified as being due to the development of the natural Kelvin-Helmholtz instability in the shear layer. Indeed, the most amplified frequency in a bi-dimensional mixing layer between two parallel flows with respective velocities $U_{1}$ and $U_{2}$ is given by: $f_{0}=\frac{1}{2}\left(U_{1}+U_{2}\right) /\left(7 \delta_{0}\right)$, where $\delta_{0}=\left|U_{1}-U_{2}\right| / \max (d U / d n)$ is the initial vorticity thickness $(n$ denotes the shear-normal direction). This formula applied in the present case to mean velocity profiles extracted at the very beginning of the flap shear layer lead to a theoretical frequency of about $3.65 \mathrm{kHz}$, in almost perfect agreement with the observed frequency. The difference in frequency between the LES and the measurements is therefore simply expected to be due to slight differences in the boundary layer profiles upstream of the flap cove at the pressure side of the main wing element, which modify the value of $\delta_{0}$. As stated previously (and observed on Figure 16, residual turbulent fluctuations are present in the experiment. They may alter the state of the pressure side boundary layer and transition process in the flap cove shear layer. Again, the overall level of the spectra is lower in the LES than in the LDV measurements at the early stages of the shear layer, but when advancing downstream in the shear layer, the agreement between the LES and LDV measurements becomes better. At location 19-4, the spectra exhibit the typical features of homogeneous turbulence and follow nicely the $-5 / 3$ power law.

Additional numerical probes have been introduced in the simulation in order to investigate pressure spectra. They are located in the slat shear layer, in the wakes of the slat and main body trailing edges, in free field around the slat and in the main wing element suction side boundary layer. The location of these probes is illustrated in Figure 23.

Figure 24 presents the evolution of the pressure spectra along the slat shear layer. Just after the cusp trailing edge, a broadband peak is present in the pressure spectrum, at about $45.5 \mathrm{kHz}$, with its first harmonic. This peak is the signature of a regular flapping of the wake at the cusp trailing edge. Moving further downstream in the shear layer, the peak gradually shifts to lower frequencies due to a redistribution of energy among a broader range of scales. Indeed, transition 
to fully-developed turbulence is clearly observed in the shear layer. It is interesting to note that at each considered station, a peak is also observed at about $58 \mathrm{kHz}$. Looking at Figure 25, it appears that this peak is linked to the vortex shedding at the slat upper trailing edge. This phenomenon is therefore responsible for the generation of acoustic waves at $58 \mathrm{kHz}$ (already observed on instantaneous visualizations in section IV.A that propagate through the slat cove. Figure 25 also exhibits a similar vortex shedding at the trailing edge of the main wing element, at a frequency of about $39 \mathrm{kHz}$.

Figure 26 provides an idea of the near-field radiated noise spectra, at the three free-field locations AC1, AC2 and AC3 (see Figure 23). The pressure spectra at these locations follow a general $f^{-2}$ decay. A strong broadband peak is observed at the slat trailing edge vortex shedding frequency $(f \simeq 58 \mathrm{kHz})$. This indicates that this phenomenon represents an important source of noise. Despite the relative coarse frequency resolution available $(\Delta f=100 \mathrm{~Hz})$, other peaks can be observed in the pressure spectra. More particularly, a peak at about $4.5 \mathrm{kHz}$ is present, as well as several of its harmonics. As discussed by Lockard et al. [14], this peak may be due to the periodicity boundary conditions used in span and can be considered as a numerical artifact. Indeed, the frequency corresponding to an acoustic wave with a wavelength equal to the spanwise extent of the computational domain $\left(\lambda_{z}=c / 4\right)$ is $4.576 \mathrm{kHz}$, which matches almost perfectly the frequency of the observed peak.

The experimental noise spectra were characterized by strong tonal peaks at $2.1 \mathrm{kHz}, 3 \mathrm{kHz}$ and $3.8 \mathrm{kHz}$ [21]. They do not appear to be reproduced by the present simulation. The presence of such tones in high-lift configuration still receives significant attention. In previous works [3, 6], it was suggested that they could be related to a feedback aero-acoustic loop in the slat cove. This analysis could unfortunately not be reproduced in the present study, where the tones are absent. It is worth noting, that the intensity of the tones was observed to be significantly dependent on the experimental facility [21]. Such tones are also not observed in recent experiments [38] of the same airfoil placed in a swept configuration (sweep angle $30^{\circ}$ ). Therefore, the presence of these tones seems to be strongly sensitive to some changes in the experimental conditions. It appears reasonable to think that there may be the same kind of dependence on the numerical parameters (e.g. numerical scheme, grid resolution). This point deserves further investigation that unfortunately could not be performed in the present study, due to the expensive cost of the simulation. It may be addressed in future works, using more affordable RANS/LES methods.

It is also worth noting the presence of a low-frequency component in the three spectra, at about $560 \mathrm{~Hz}$. As discussed by Deck and Laraufie [6], this may be the signature of a coupled self-sustained oscillation mechanism between the slat and flap areas. The authors derived the following expression for the Strouhal number associated to this coupling:

$$
S t_{1 \leftrightarrow 2}=\frac{1-M_{\infty}^{2}}{2 M_{\infty}},
$$

where $M_{\infty}$ is the free-stream Mach number. The Strouhal number $S t_{1 \leftrightarrow 2}$ is based on the clean airfoil chord $c$ and the free-stream velocity $U_{\infty}$. The theoretical value predicted by $\left[5\right.$ in the present case is $S t_{1 \leftrightarrow 2}=2.72$, which agrees very 
nicely with the low-frequency component observed in Figure 26 This therefore appears to support the existence of an acoustic feedback mechanism between the slat and the flap areas, although a longer sampling time would be necessary to perform a finer spectral analysis.

\section{Analysis of the main wing boundary layer}

As it was already discussed in section IV.A transition of the boundary layer is observed on the main wing suction side at about $x / c=0.2$. Figure 27 presents a top view of the flow near the transition location, using a value of the $Q$-criterion of $Q=50,000 U_{\infty}^{2} / c^{2} \simeq 0.034 U_{e}^{2} / \delta^{2}$, where $\delta$ and $U_{e}$ are respectively the boundary layer thickness and the velocity at the edge of the boundary layer, estimated at $x / c=0.193$. This value of $Q$ makes it possible to distinguish the coherent turbulent structures present in the very-near wall region from the wake structures. Transition to turbulence is clearly evidenced, with a significant variability of its streamwise location along the span. This transition actually results from two combined physical phenomena:

1) Looking closely at the airfoil geometry in this area, a sudden change of curvature of the airfoil surface is observed at $x / c \simeq 0.193$. It actually corresponds to the location of the slat trailing-edge in the (retracted) cruise configuration. This change of curvature is evidenced in Figure 28 (right), using a different aspect ratio between the $x$ and $y$ axis. At this location, a sudden growth of the friction coefficient and of the Reynolds number based on the local momentum thickness $R e_{\theta}$ is observed (see Figure 28). The resolved Reynolds stresses are also experiencing a fast increase after the geometrical change, as evidenced in Figure 28 (left). These quantities are here plotted at a height $h / c=6.5 \times 10^{-4}$ above the wall, corresponding to the maximum value of the resolved kinetic energy $k$ just downstream of the change of curvature. It is worth noting that the resolved Reynolds stresses have been re-computed in the frame related to the wall, i.e. $u$ denotes the local tangential component of velocity and $v$ is the normal one.

It also appears that the mean friction coefficient $C_{f}$ almost vanishes between $x / c=0.193$ and $x / c=0.21$. This distribution resembles the one encountered in transitional separation bubbles [35], although $C_{f}$ remains strictly positive, i.e. no mean flow separation is present. However, looking closely at Figure 27, instantaneous separated areas are observed downstream of the change of curvature. Several two-dimensional vortices are indeed present, in some flow regions organized as laminar separation bubbles. An almost immediate transition to turbulence then occurs just downstream of these localized separated areas.

Figure 29 presents the near-wall velocity spectra, computed at the first cell center off-the-wall, for several $x / c$ locations. A huge increase of the resolved kinetic energy is observed between the leading edge and the transition location, by several orders of magnitude. Near the leading-edge of the wing, the near-wall energy spectra have a very low level and follow a general $f^{-5 / 3}$ trend. This is most probably the near-wall signature of the slat wake turbulence fluctuations passing above the main wing. Just downstream of the wall change of curvature, a sudden 
increase of the overall level of the turbulent kinetic energy spectra occurs. At $x / c=0.204$, i.e. where local separated areas of the flow are observed, a broadband hump is present in the energy spectra, at a frequency $f_{v} \simeq 20 \mathrm{kHz}$, or $f_{v} \delta / U_{e} \simeq 0.1$, where $\delta$ and $U_{e}$ are respectively the boundary layer thickness and the velocity at the edge of the boundary layer, at $x / c=0.204$. This hump in the spectra is most probably due to the regular passing of localized two-dimensional vortices evidenced in Figures 27 and 29 (bottom). Further downstream, a spectral broadening of energy is observed; the energy spectra then exhibit a short $f^{-1}$ range, which is most probably the near-wall signature of the large scales of the turbulent boundary layer.

2) It is worth noting that several turbulent spots are already present in the near-wall region, upstream of the change of curvature. These spots are actually due to a bypass transition of the boundary layer, under the action of the slat wake fluctuations. This point is illustrated by Figure 30 , presenting iso-contours of the streamwise component of vorticity, in several transverse $y-z$ planes located in the transition area. Upstream of the wall change of curvature, it is noticeable that the near-wall region already presents some level of streamwise vorticity. In the slat wake, several equally-spaced large packets of vortices are observed. They correspond to the streamwise vortices shed from the slat cove that have already mixed with the slat trailing-edge wake. Some pairings of these streamwise vortices are also observed when moving downstream. At all streamwise locations, some of these large packet of vortices reach the near-wall region, yielding localized turbulent spots in the boundary layer. At the last plotted location $x / c=0.25$, the mixing between the boundary layer and the slat wake is clearly visible.

Further downstream, the boundary layer reaches a fully turbulent state. Figure 31 presents the streamwise evolution of the skin-friction coefficient $C_{f}$ and of the Reynolds number based on the momentum thickness $\operatorname{Re}_{\theta}$ (computed using the local values of velocity at the edge of the boundary layer). Downstream of the transition area, $R e_{\theta}$ grows linearly and reaches a value of 4000, before a sudden increase near the trailing edge. Figure 32 presents the predicted mean tangential velocity profiles (left) and resolved RMS velocity fluctuations (right), in wall units, at several streamwise stations after the transition location. Again, the velocity components and Reynolds stresses have been projected in the local frame of the wall ( $u$ denotes the tangential velocity component, $v$ the wall-normal component and $w$ the spanwise one). Since there is no experimental value of the skin friction velocity $u_{\tau}$ available, the LDV measurement along the rake 35-6 has been normalized here using the value of $u_{\tau}$ predicted by the LES at that station. The main characteristics of a canonical turbulent boundary layer subjected to an adverse pressure gradient are recovered, with a very nice agreement with the theoretical wall laws. Nevertheless, it is worth noting that the outer part of the boundary layer does not fully reach a canonical behavior: indeed, the RMS fluctuations do not fully vanish in this region (typically above $y^{+}=1000$ in this case). This is the signature of the fluctuations of the slat wake, still present along the entire airfoil chord.

Finally, Figure 33 shows the wall pressure spectra computed at the suction side, at several streamwise stations of the turbulent boundary layer of the main wing element. Using a scaling based on the kinematic viscosity $v$ and the local values of the friction velocity $u_{\tau}$ and wall shear stress $\tau_{w}$, all the spectra collapse quite well and follow nicely 
well-established power laws [39-41].

\section{Conclusion and future work}

A highly-resolved LES of the three-element LEISA2 high-lift airfoil has been performed and presented in this paper. To the author's knowledge, this simulation represents the first one of such a configuration with a direct resolution of the main physical mechanisms involved in the flow dynamics. Many phenomena are therefore resolved, including the development and transition process of the slat and flap shear layers, their interaction with solid surfaces, the spatial development of the slat wake, the transition and turbulent boundary layer development on the main wing element, the flow on the flap surface and the flap wake. All these complex flow features interact with each other and are therefore strongly coupled. The appropriate resolution of the turbulent boundary layer dynamics on the suction side of the main wing represents a big challenge by itself, due to the fine near-wall coherent structures involved in turbulence production that have to be resolved over a large spatial extent.

The comparison of the numerical results with experimental ones obtained in Onera's F2 aerodynamic wind tunnel indicate that the flow is generally well predicted by the simulation. The simulated flow inside the slat and flap coves presents a very satisfactory agreement with the experimental results, for the mean flow, turbulence statistics and velocity spectra. The turbulent boundary layer at the suction side of the main wing element also appears to be well reproduced by the simulation.

Noticeable differences between the flow predicted by the simulation and the measurements have been observed in the flap region. The flow predicted by the LES does not exhibit any separation on the flap suction side, while two different behaviors of the flow over the flap have been observed experimentally. On the one hand, massive separation was observed in the PIV measurements. On the other hand, the LDV measurements do not show evidences of such a separation. The flap separation therefore seems to be very sensitive to external perturbations, as already discussed in past studies [7].

Several physical phenomena associated with turbulence and noise generation have been highlighted thanks to the numerical simulation, which therefore appears as a valuable tool for future studies that will go deeper in the physical analysis of the flow. For instance, it was shown that the flow over the main wing involves very complex physical phenomena such as boundary layer transition, as well as the mixing of the slat wake and the boundary layer further downstream. The boundary layer transition actually results from two combined phenomena. The first one is linked to a sudden change of curvature of the wall, yielding instantaneous laminar separation bubbles, dispatched along the span. The second one is a bypass transition process, under the action of slat wake turbulent structures penetrating the boundary layer. The slat area has been highlighted as being the major contributor to the radiated noise. Moreover, a large-scale coupled self-sustained oscillation mechanism between slat and flap cavities has been evidenced according to Figure 26 (see the discussion in the previous section). This acoustic feedback between the slat and flap coves has 
been previously observed by other authors [6] and is recovered by the present LES. This suggests that future numerical studies should resolve the full configuration and not only focus on the slat cove dynamics.

Future works will also focus on the analysis of the radiated noise obtained from the LES, by applying integral extrapolation techniques, such as the Ffowcs-Williams and Hawkings integration, based on several sampling surfaces, either porous surfaces introduced around the airfoil, or the rigid airfoil surface itself. However, this will require significantly longer data sampling, which is not achievable at this time.

The present wall-resolved LES offers an important database for data comparison for other numerical approaches, in addition to the physical investigation of the flow. Indeed, experimental installation effects, such as the walls in closed wind tunnels, jet deflection in open-jet facilities, brackets or lateral supporting plates, always introduce a degree of bias compared to ideal numerical conditions. The present high-fidelity numerical solution may therefore constitutes a valuable additional validation set, allowing lower resolution simulations to cross compare with and separate physical phenomena from numerical effects.

In future works, we will indeed focus on the comparison of the results obtained with more affordable calculations based on hybrid RANS/LES or wall-modeled LES methods, where much coarser grids can be used thanks to a RANS resolution of the near-wall region, or a near-wall model. The quantitative information provided about the transition process and boundary layer development on the main wing suction side will therefore be very useful for the improvement and validation of such methodologies.

\section{Acknowledgments}

This work was achieved under internal Onera's funding in the framework of the Onera-DLR Common Research Projet LEISA2. It was also granted access to the HPC resources of CINES under the allocation c20132a7049 made by GENCI (Grand Equipement National de Calcul Intensif).

The authors are grateful to Onera's F2 windtunnel team who contributed to elaborate the LEISA2 experimental database which is extensively used for the validation of the present computation.

The authors also address special thanks to Dr. I. Mary for his valuable assistance with the numerical solver FUNk and to Dr. S. Deck and Dr. V. Gleize for stimulating technical discussions. 


\section{References}

[1] Terracol, M., and Manoha, E., "Wall-resolved Large Eddy Simulation of a highlift airfoil: detailed flow analysis and noise generation study,” AIAA Paper 2014-3050, 20th AIAA/CEAS Aeroacoustics Conference, 2014.

[2] Dobrzynski, W., "Almost 40 years of airframe noise research: what did we achieve?" Journal of aircraft, Vol. 47, No. 2, 2010, pp. 353-367. doi:10.2514/1.44457.

[3] Terracol, M., Manoha, E., and Lemoine, B., "Investigation of the unsteady flow and noise generation in a slat cove," AIAA Journal, Vol. 54, No. 2, 2015, pp. 469-489. doi:10.2514/1.J053479.

[4] Terracol, M., Labourasse, E., Manoha, E., and Sagaut, P., "Simulation of the 3D unsteady flow in a slat cove for noise prediction," AIAA Paper 2003-3110, 9th AIAA/CEAS Aeroacoustics Conference and Exhibit, 2003.

[5] Imamura, T., Enomoto, S., Yokokawa, Y., and Yamamoto, K., "Three-Dimensional Unsteady Flow Computations Around a Conventional Slat of High-Lift Devices,” AIAA Journal, Vol. 46, 2008, pp. 1045-1053. doi:10.2514/1.25660.

[6] Deck, S., and Laraufie, R., "Numerical investigation of the flow dynamics past a three-element aerofoil," Journal of Fluid Mechanics, Vol. 732, 2013, pp. 401-444. doi:10.1017/jfm.2013.363.

[7] Deck, S., "Zonal Detached-Eddy Simulation of the Flow Around a High-Lift Configuration," AIAA Journal, Vol. 43, 2005 , pp. 2372-2384. doi:10.2514/1.16810.

[8] Zhong, B., Scheurich, F., Titarev, V., and Drikakis, D., “Turbulent Flow Simulations Around a Multi-Element Airfoil Using URANS, DES and ILES Approaches,” AIAA Paper 2009-3799, 19th AIAA Computational Fluid Dynamics Conference, 2009.

[9] Knacke, T., and Thiele, F., "Time-Resolved 3D Simulation of an Aircraft Wing with Deployed High-Lift System," Turbulence and Interactions Proceedings the TI 2009 Conference, edited by P. Sagaut, T. Lê, and S. M. Deville, 2010, pp. $223-230$.

[10] Knacke, T., and Thiele, F., "Numerical Analysis of Slat Noise Generation," AIAA Paper 2013-2162, 19th AIAA/CEAS Aeroacoustics Conference, Berlin, Germany, 2013.

[11] Choudhari, M., and Khorrami, M., "Effect of Three-Dimensional Shear-Layer Structures on Slat Cove Unsteadiness," AIAA Journal, Vol. 45, 2007, pp. 2174-2186. doi:10.2514/1.24812.

[12] Lockard, D., and Choudhari, M., "Noise Radiation from a Leading-Edge Slat," AIAA Paper 2009-3101, 15th AIAA/CEAS Aeroacoustics Conference, Miami, FL, USA, 11-13 May, 2009.

[13] Lockard, D., and Choudhari, M., “The Effect of Cross Flow on Slat Noise,” AIAA Paper 2010-3835, 16th AIAA/CEAS Aeroacoustics Conference, 2010.

[14] Lockard, D. P., Choudhari, M. M., and Buning, P. G., "Influence of spanwise boundary conditions on slat noise simulations," AIAA Paper 2015-3136, 21st AIAA/CEAS Aeroacoustics Conference, 2015. 
[15] Ashton, N., West, A., and Mendonça, F., "Flow Dynamics Past a 30P30N Three-Element Airfoil Using Improved Delayed Detached-Eddy Simulation,” AIAA Journal, 2016, pp. 3657-3667. doi:10.2514/1.J054521.

[16] Terracol, M., Manoha, E., Murayama, M., and Yamamoto, K., "Aeroacoustic calculations of the 30P30N high-lift airfoil using hybrid rans/les methods: modeling and grid resolution effects," AIAA Paper 2015-3132, 21st AIAA/CEAS Aeroacoustics Conference, 2015.

[17] Sakai, R., Ishida, T., Murayama, M., Ito, Y., and Yamamoto, K., "Effect of Subgrid Length Scale in DDES on Aeroacoustic Simulation around Three-Element Airfoil,” AIAA Paper 0756-2018, 2018 AIAA Aerospace Sciences Meeting, 2018.

[18] Zhang, Y., Chen, H., Wang, K., and Wang, M., “Aeroacoustic prediction of a multi-element airfoil using wall-modeled large-eddy simulation,” AIAA Journal, 2017, pp. 4219-4233. doi:10.2514/1.J055853.

[19] Murayama, M., Yokokawa, Y., Ito, Y., Yamamoto, K., Takaishi, T., and Ura, H., "Study on Noise Generation from Slat Tracks Using a High-Lift Wing Model,” AIAA Paper 2015-3141, 21st AIAA/CEAS Aeroacoustics Conference, 2015.

[20] Satti, R., Li, Y., Shock, R., and Noelting, S., "Computational Aeroacoustic Analysis of a High-Lift Configuration,” AIAA Paper 2008-34, 46th AIAA Aerospace Sciences Meeting and Exhibit, 2008.

[21] Manoha, E., and Pott-Pollenske, M., "LEISA2: an experimental database for the validation of numerical predictions of slat unsteady flow and noise," AIAA Paper 2015-3137, 21st AIAA/CEAS Aeroacoustics Conference, 2015.

[22] Choudhari, M., and Lockard, D., "Simulations \& measurements of airframe noise: a BANC workshops perspective," NATO Specialists Meeting on "Progress and Challenges in Validation Testing for Computational Fluid Dynamics" (AVT-246); 26-28 Sep.; Zarazoga; Spain, 2016.

[23] Wild, J., Pott Pollenske, M., and Nagel, B., “An integrated design approach for low noise exposing high-lift devices,” AIAA Paper 2006-2843, 3rd AIAA Flow Control Conference, 2006.

[24] Yser, P., and Bailly, C., "High-Order Variational Multiscale Model in Finite Elements Applied to the LEISA-2 Configuration," AIAA Journal, Vol. 56, No. 12, 2018, pp. 5000-5012. doi:10.2514/1.J057090.

[25] Manoha, E., M.Terracol, , Lemoine, B., Griffon, I. L., and Garrec, T. L., "Slat noise measurement and numerical prediction in the VALIANT programme," AIAA Paper 2012-2100, 18th AIAA/CEAS Aeroacoustics Conference (33rd AIAA Aeroacoustics Conference), Colorado Springs, CO, 2012.

[26] Terracol, M., and Deck, S., "Numerical Investigation of the Flow around a Three-Element High-Lift Airfoil Using Two Zonal Hybrid RANS/LES Methods: ZDES and NLDE," Progress in Hybrid RANS-LES Modelling, Notes on Numerical Fluid Mechanics and Multidisciplinary Design, Vol. 117, edited by S. Fu, W. Haase, S.-H. Peng, and D. Schwamborn, Springer Berlin Heidelberg, 2012, pp. 345-355. doi:10.1007/978-3-642-31818-4_30.

[27] Spalart, P., and Allmaras, S., “A One Equation Turbulence Model for Aerodynamic Flows,” AIAA Paper 92-0439, 1992. 
[28] Lenormand, E., Sagaut, P., and Ta Phuoc, L., "Large-Eddy Simulation of compressible channel flow at moderate Reynolds number," Int. J. Numer. Methods Fluids, Vol. 32, 2000, pp. 369-406. doi:10.1002/(SICI)1097-0363(20000229)32:4\%3C369:: AID-FLD943\%3E3.0.CO;2-6.

[29] Lenormand, E., Sagaut, P., Ta Phuoc, L., and Comte, P., "Subgrid-Scale Models for Large-Eddy Simulation of Compressible Wall Bounded Flows," AIAA journal, Vol. 38, No. 8, 2000, pp. 1340-1350. doi:10.2514/2.1133.

[30] Mary, I., and Sagaut, P., “Large Eddy Simulation of Flow around an airfoil Near Stall,” AIAA journal, Vol. 40, No. 6, 2002 , pp. 1139-1145. doi:10.2514/2.1763.

[31] Choi, H., and Moin, P., "Effects of the computational time step on numerical solutions of turbulent flow," Journal of Computational Physics, Vol. 113, No. 1, 1994, pp. 1-4. doi:10.1006/jcph.1994.1112.

[32] Daude, F., Mary, I., and Comte, P., "Self-Adaptive Newton-based iteration strategy for the LES of turbulent multi-scale flows," Computers \& Fluids, Vol. 100, 2014, pp. 278-290. doi:10.1016/j.compfluid.2014.04.028.

[33] Sillero, J. A., Jiménez, J., and Moser, R. D., “One-point statistics for turbulent wall-bounded flows at Reynolds numbers up to $\delta^{+} \simeq 2000, "$ Physics of Fluids, Vol. 25, No. 10, 2013, p. 105102. doi:10.1063/1.4823831.

[34] Uzun, A., and Malik, M. R., "Large-Eddy Simulation of Flow over a Wall-Mounted Hump with Separation and Reattachment," AIAA Journal, 2017, pp. 715-730. doi:10.2514/1.J056397.

[35] Laurent, C., Mary, I., Gleize, V., Lerat, A., and Arnal, D., "DNS database of a transitional separation bubble on a flat plate and application to RANS modeling validation,” Computers \& Fluids, Vol. 61, 2012, pp. 21 - 30. doi:10.1016/j.compfluid.2011.07. 011.

[36] Meyers, J., and Sagaut, P., "Is plane-channel flow a friendly case for the testing of large-eddy simulation subgrid-scale models?" Physics of Fluids, Vol. 19, No. 4, 2007, p. 048105. doi:10.1063/1.2722422.

[37] Rezaeiravesh, S., and Liefvendahl, M., "Effect of grid resolution on large eddy simulation of wall-bounded turbulence," Physics of Fluids, Vol. 30, No. 5, 2018, p. 055106. doi:10.1063/1.5025131.

[38] Manoha, E., Davy, R., Pott-Pollenske, M., and Barré, S., "SWAHILI: an experimental aerodynamic and acoustic database of a 2D high lift wing with sweep angle and flap side edge,” 2018 AIAA/CEAS Aeroacoustics Conference, 2018, p. 3459.

[39] Goody, M., "Empirical spectral model of surface pressure fluctuations," AIAA Journal, Vol. 42, No. 9, 2004 , pp. $1788-1794$. doi:10.2514/1.9433.

[40] Blake, W., "Turbulent boundary-layer wall-pressure fluctuations on smooth and rough walls," Journal of Fluid Mechanics, Vol. 44, No. 04, 1970, pp. 637-660. doi:10.1017/S0022112070002069.

[41] Bradshaw, P., "'Inactive' motion and pressure fluctuations in turbulent boundary layers," Journal of Fluid Mechanics, Vol. 30, 1967, pp. 241-258. doi:10.1017/S0022112067001417. 


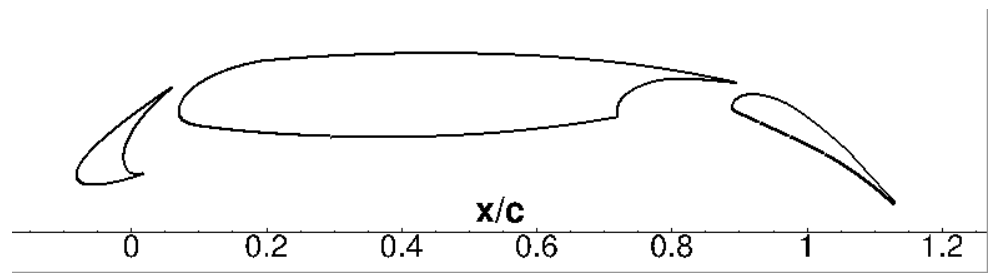

Fig. 1 Section of the LEISA2 high-lift airfoil.
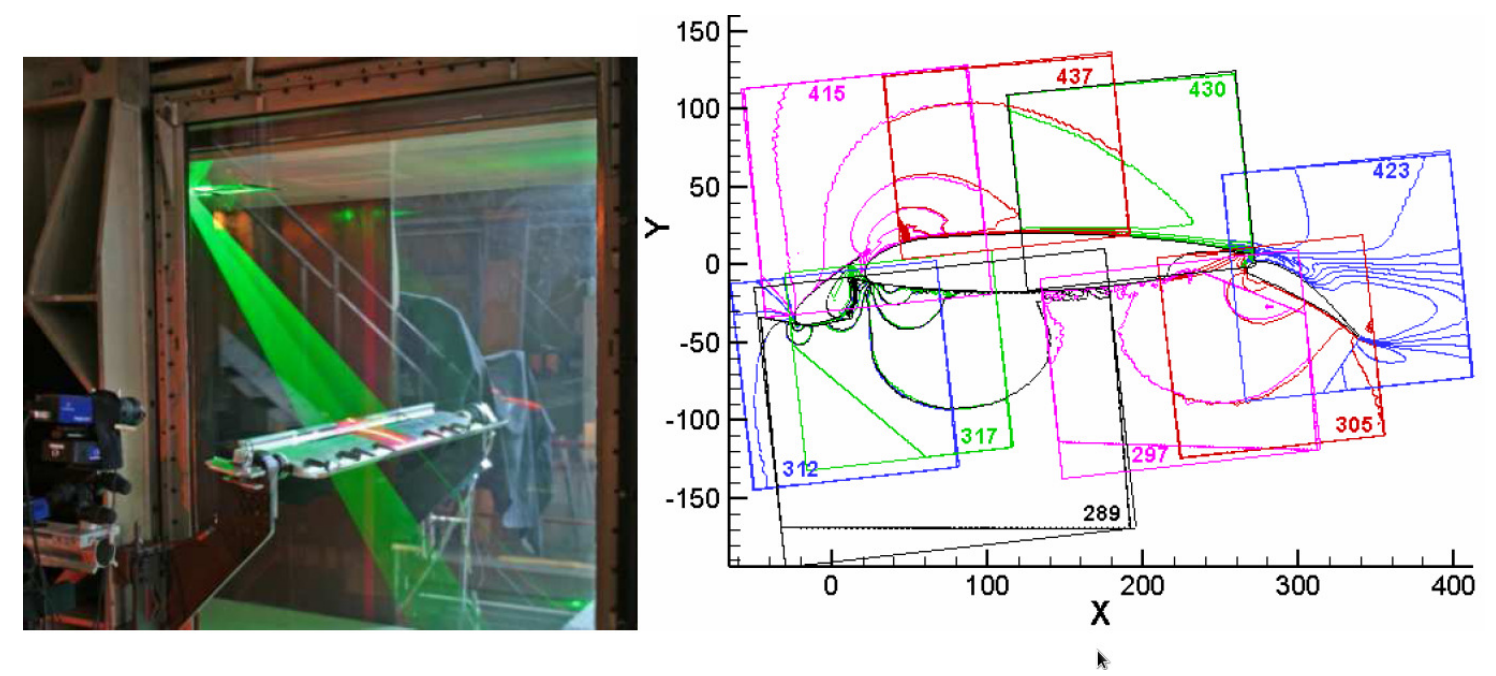

Fig. 2 Left: 2D PIV test set-up; Right: mosaic of individual PIV maps necessary to cover the mean flow. See reference[21] for more details.

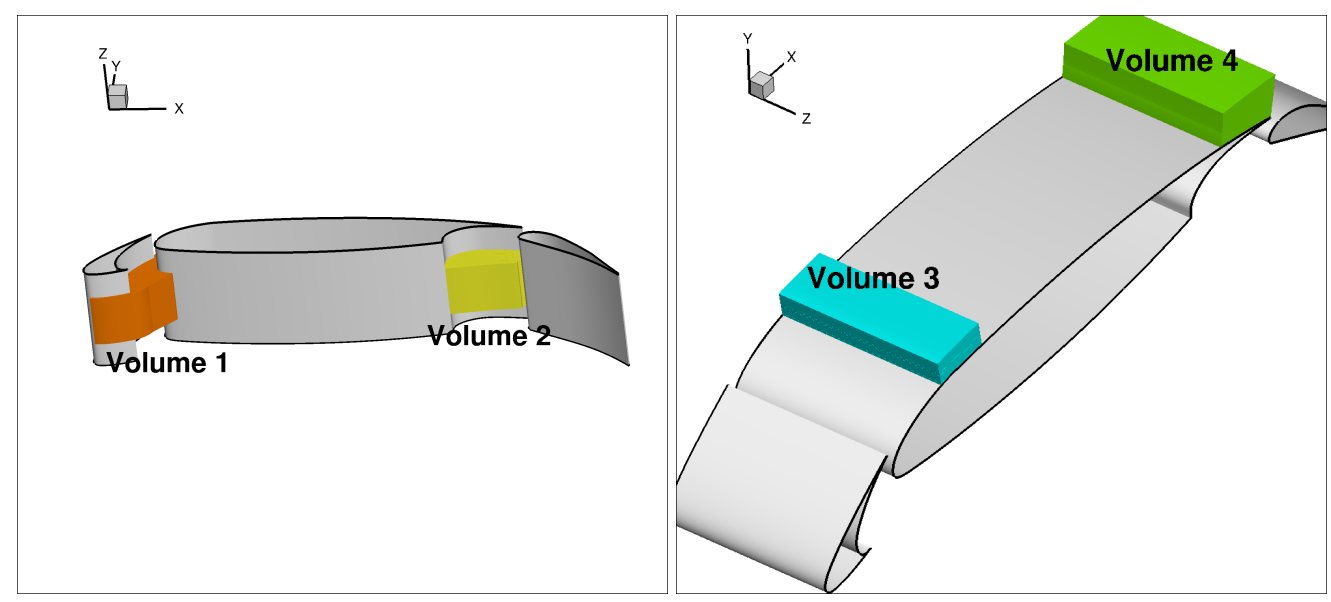

Fig. 3 Reduced data extraction volumes used for 3D visualizations. 

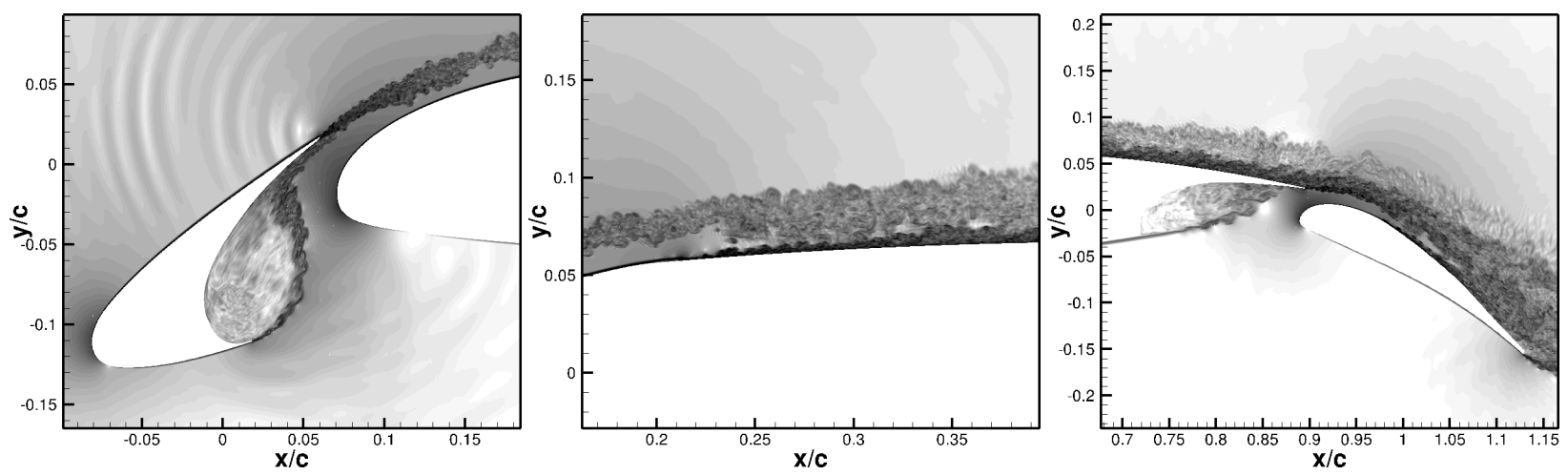

Fig. 4 Numerical Schlieren visualizations in the mid-span plane.

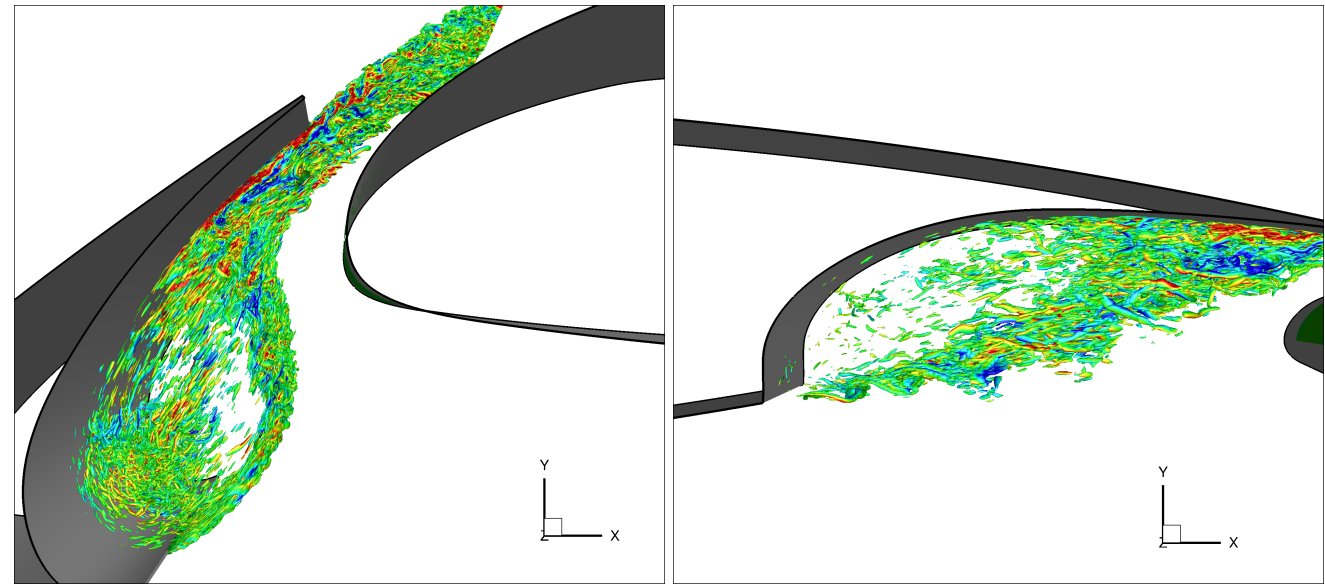

Fig. 5 Instantaneous 3D view of the flow (iso-surface of the $Q$-criterion colored by the spanwise velocity). Left: slat cove region $\left(Q^{*}=20000\right)$; right: flap cove region $\left(Q^{*}=10000\right)$

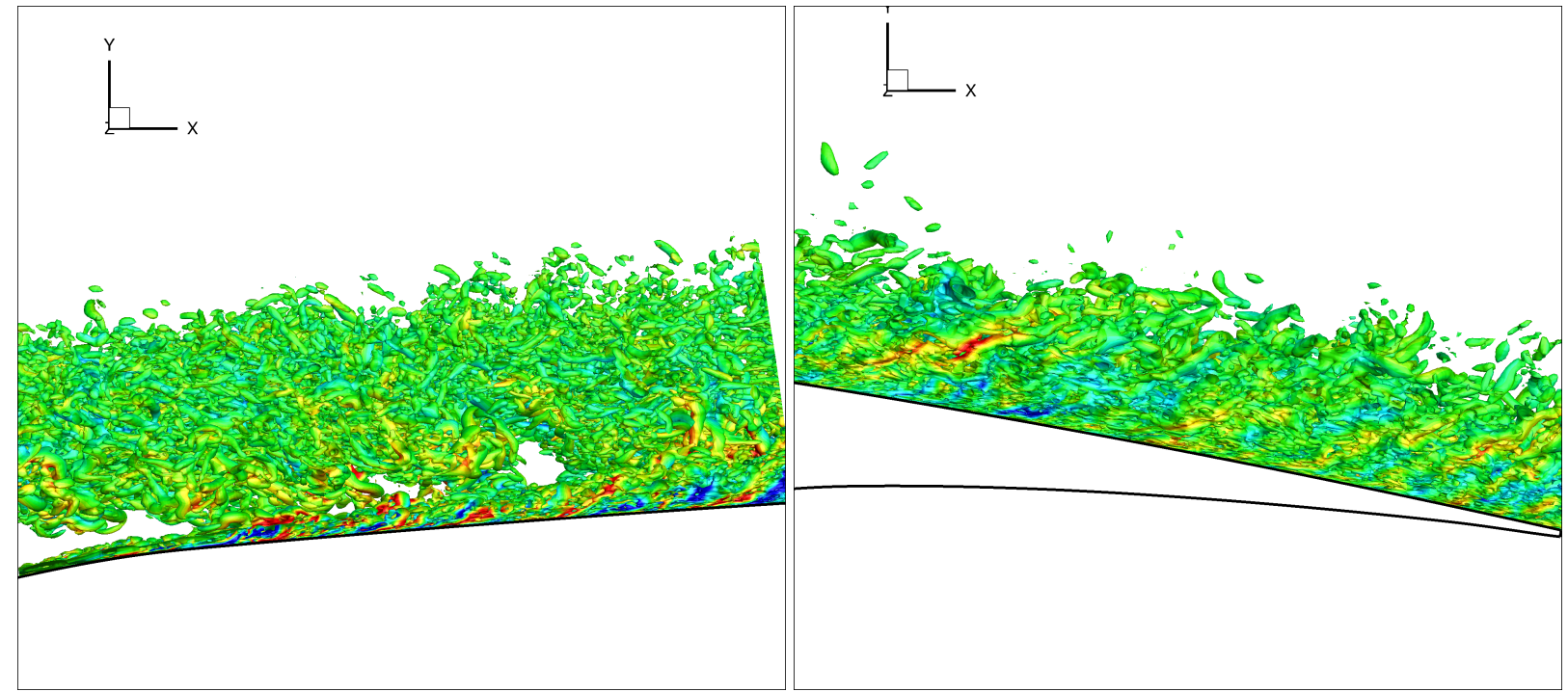

Fig. 6 Instantaneous 3D view of the flow (iso-surface $Q^{*}=20000$ colored by the spanwise velocity). Left: side view of the suction side near $x / c=0.2$; right: side view of the suction side close to the main wing trailing-edge. 


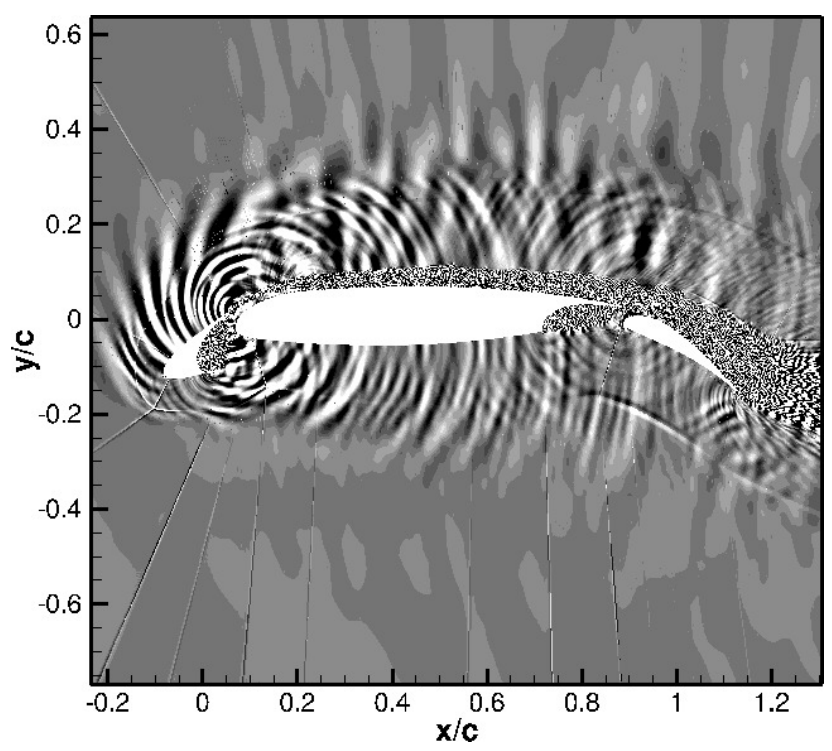

Fig. 7 Instantaneous view of the dilatation field $\operatorname{div}(\rho \vec{u})$ in the mid-span plane.

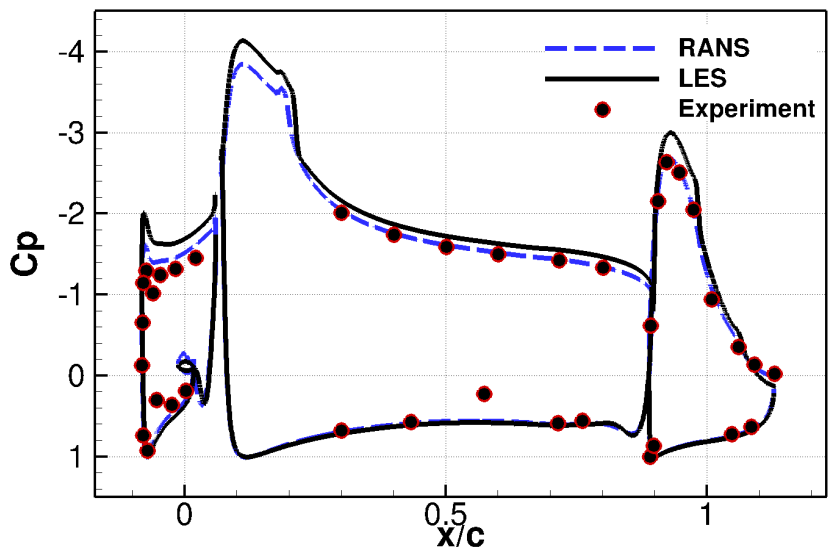

Fig. 8 Mean wall-pressure coefficient distribution 

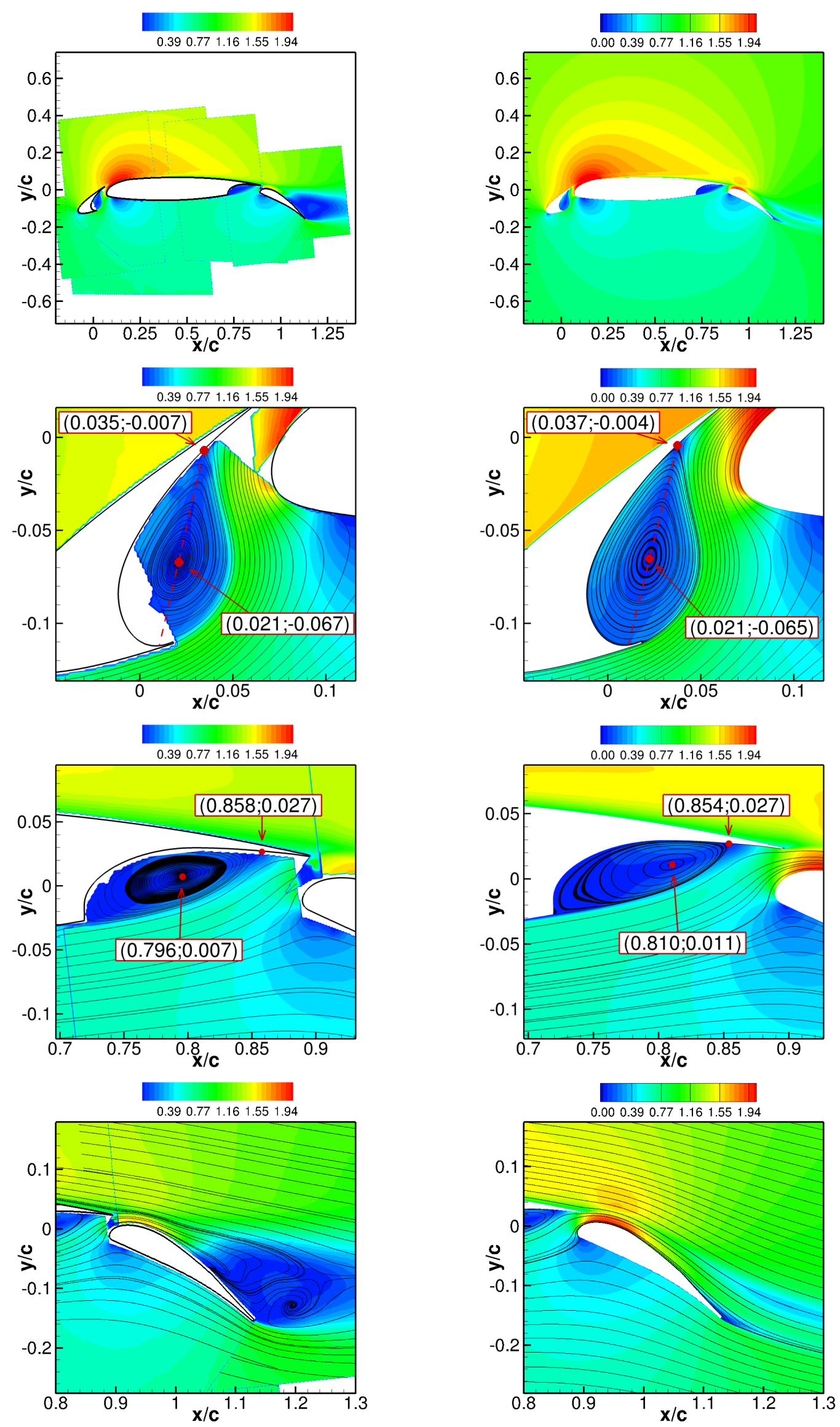

Fig. 9 Mean flow streamlines and velocity magnitude distribution. Left: PIV measurements; Right: LES result. 

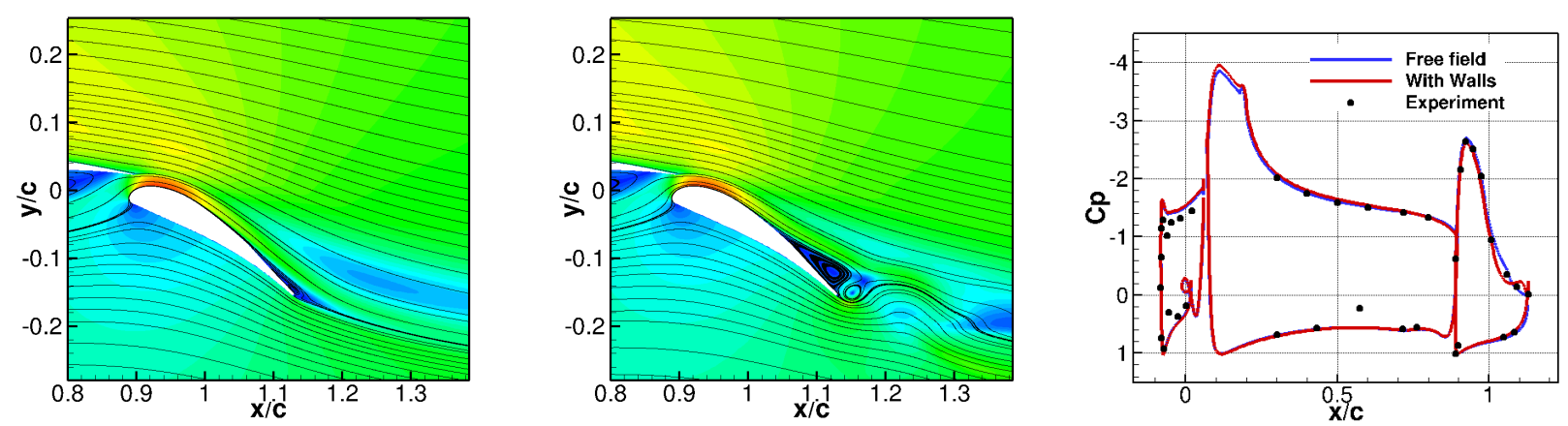

Fig. 10 Mean flow streamlines and velocity magnitude distribution in the flap area. Left: RANS calculation in free field; Center: RANS calculation with wind tunnel walls; Right: Pressure coefficient distribution.

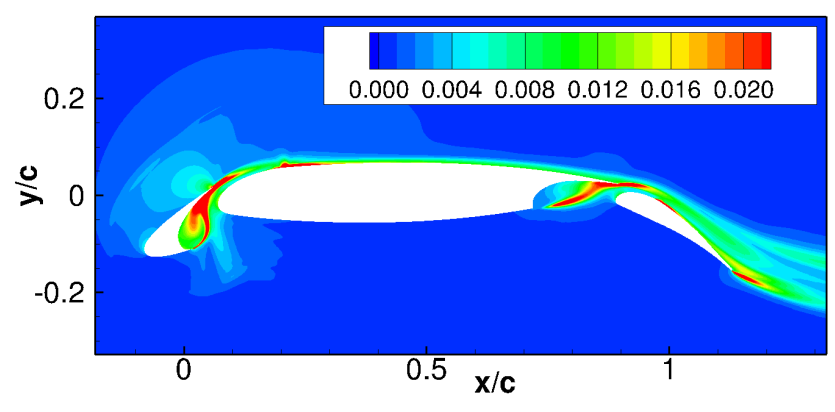

Fig. 11 RMS pressure fluctuation distribution (normalized by $\rho_{\infty} U_{\infty}^{2}$ )
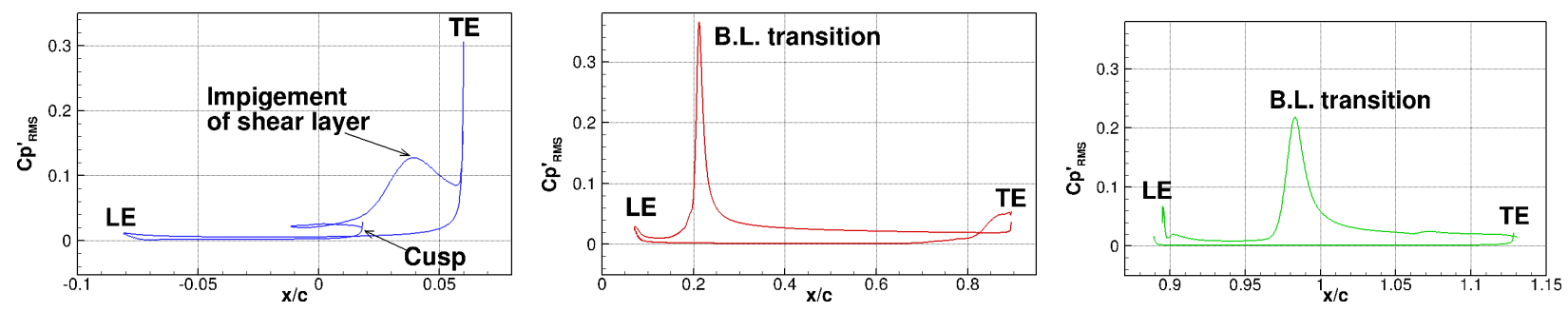

Fig. 12 Resolved RMS wall-pressure coefficient distribution. Left: slat; center: main wing element; right: flap. 

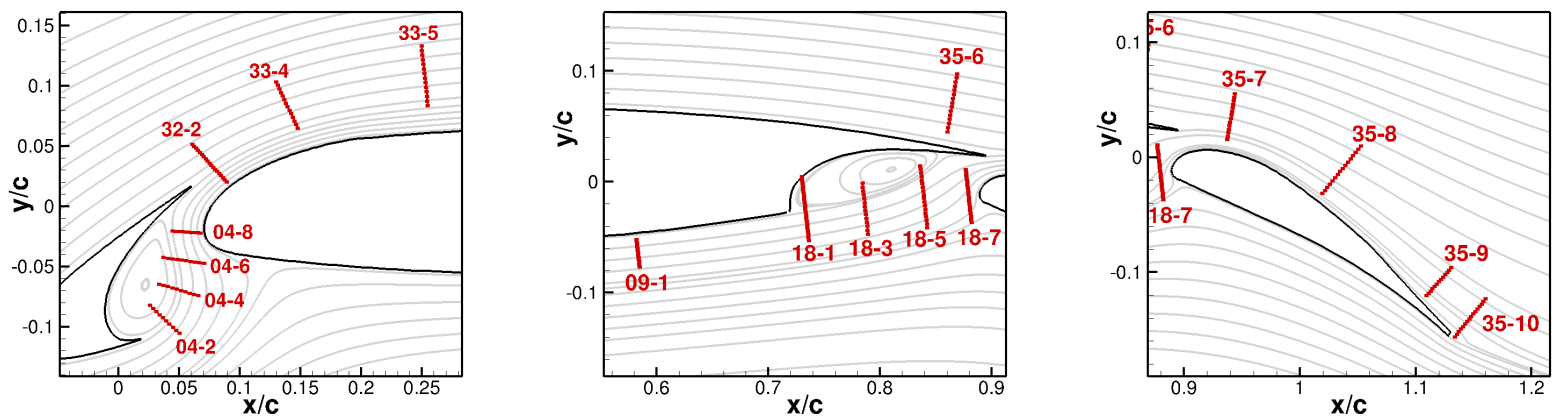

Fig. 13 Extraction rakes retained for the analysis of flow statistics and comparison against steady LDV measurements. 

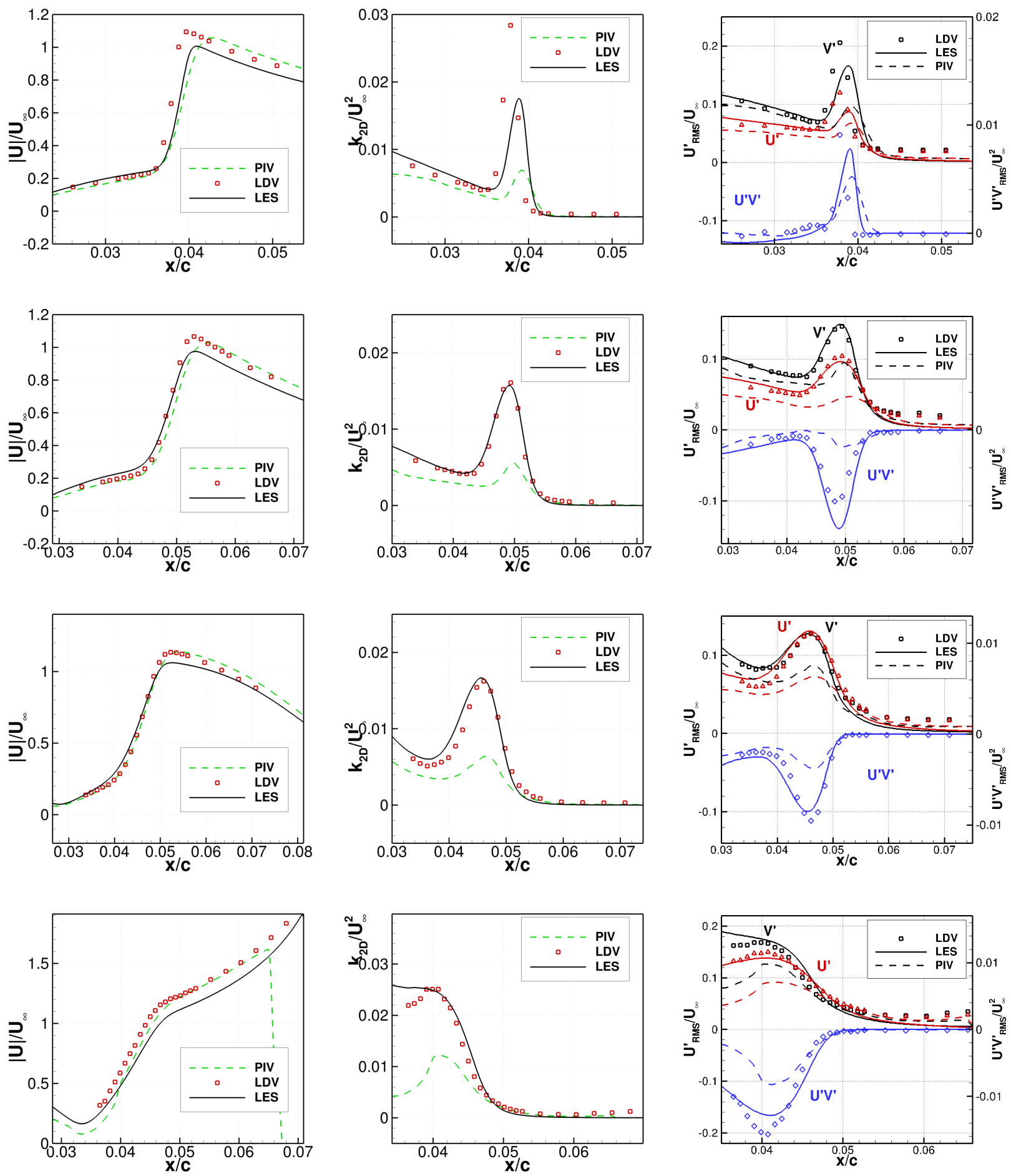

Fig. 14 Mean and RMS velocity profiles along four different rakes in the slat main shear layer (see Figure 13). From top to bottom: rakes 04-2, 04-4, 04-6, 04-8. 

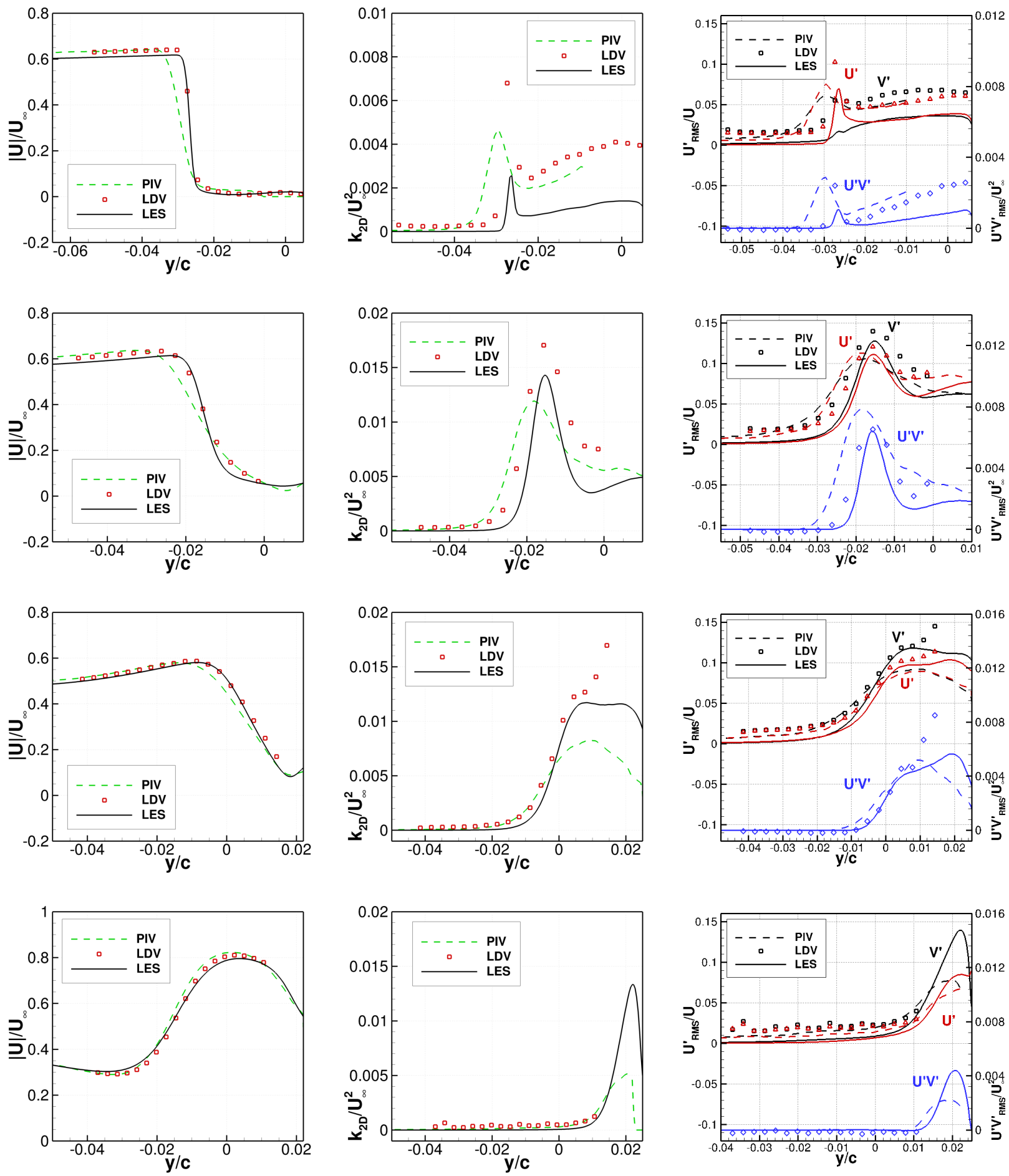

Fig. 15 Mean and RMS velocity profiles along four different rakes in the flap cove (see Figure 13). From top to bottom: rakes 18-1, 18-3, 18-5, 18-7. 

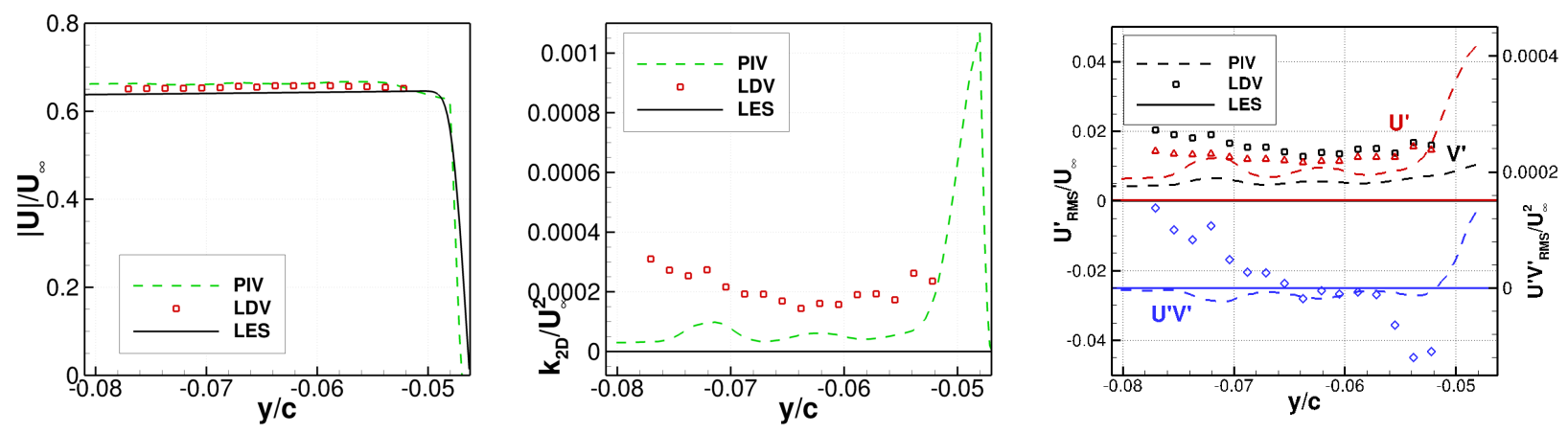

Fig. 16 Mean and RMS velocity profiles at the pressure side of the main wing body: rake 09-1 (see Figure 13). 

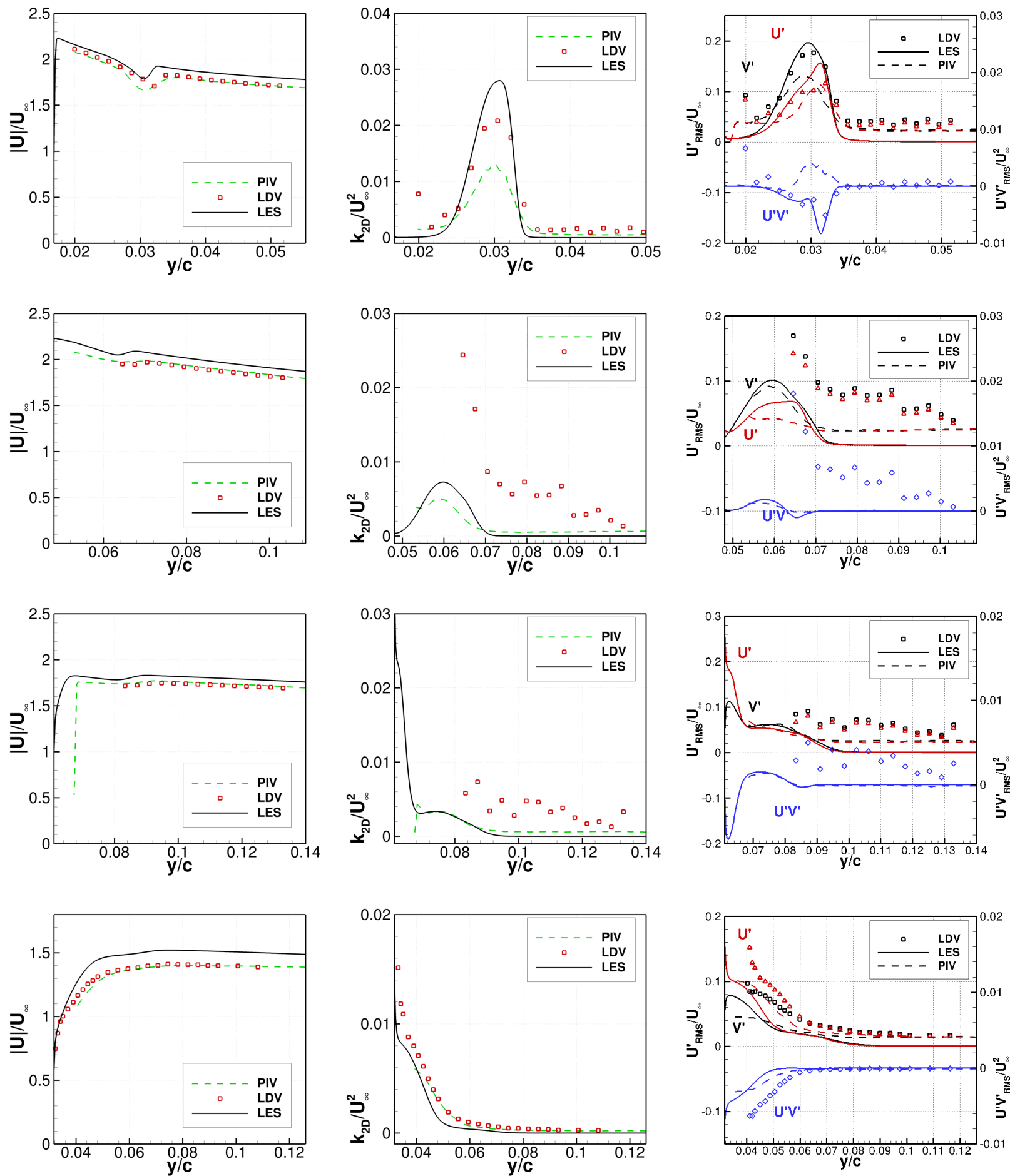

Fig. 17 Mean and RMS velocity profiles along four different rakes at the suction side of the main wing body (see Figure 13). From top to bottom: rakes 32-2, 33-4, 33-5, 35-6. 

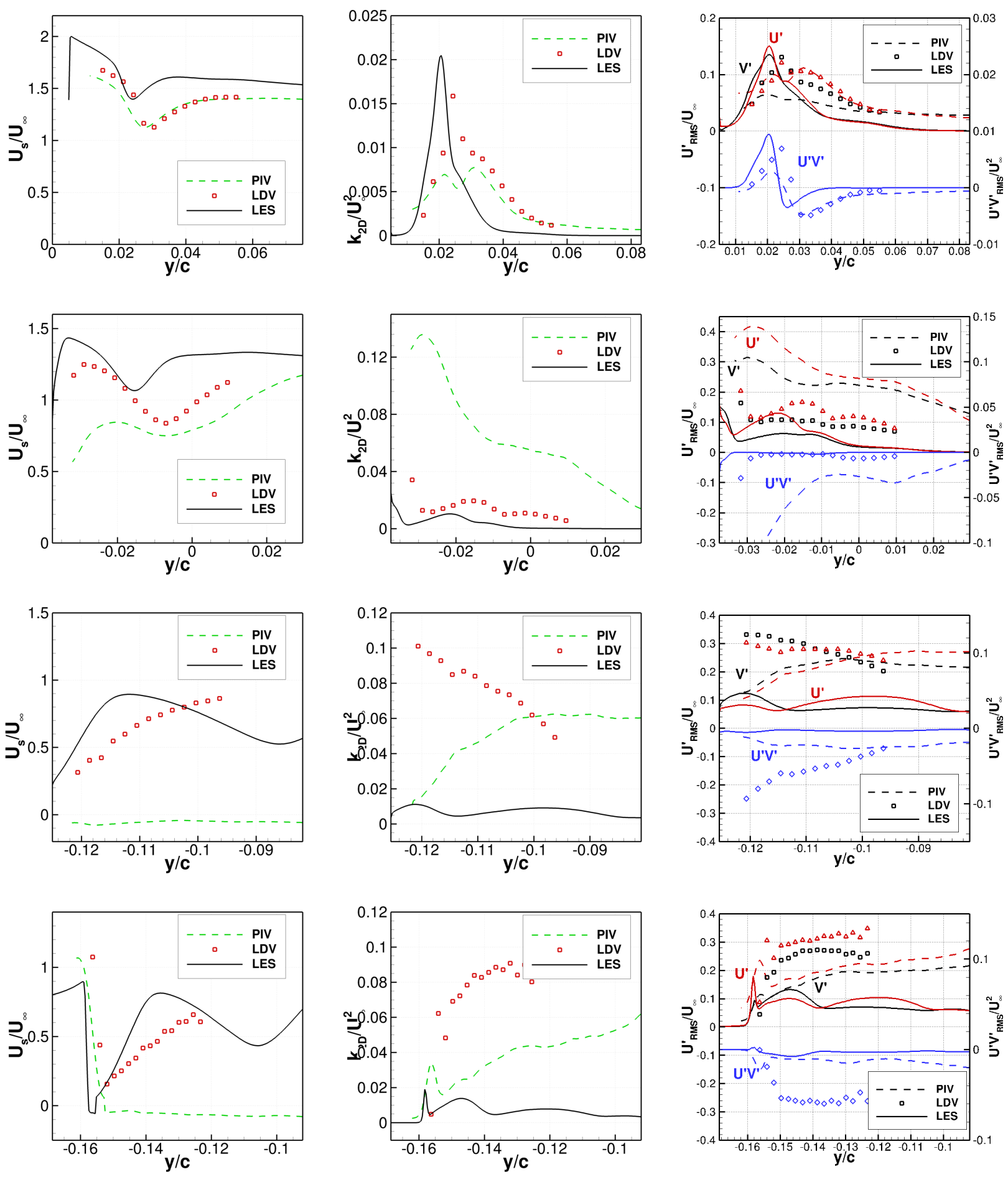

Fig. 18 Mean and RMS velocity profiles along four different rakes in the flap main shear layer (see Figure 13). From top to bottom: rakes 35-7, 35-8, 35-9, 35-10. 

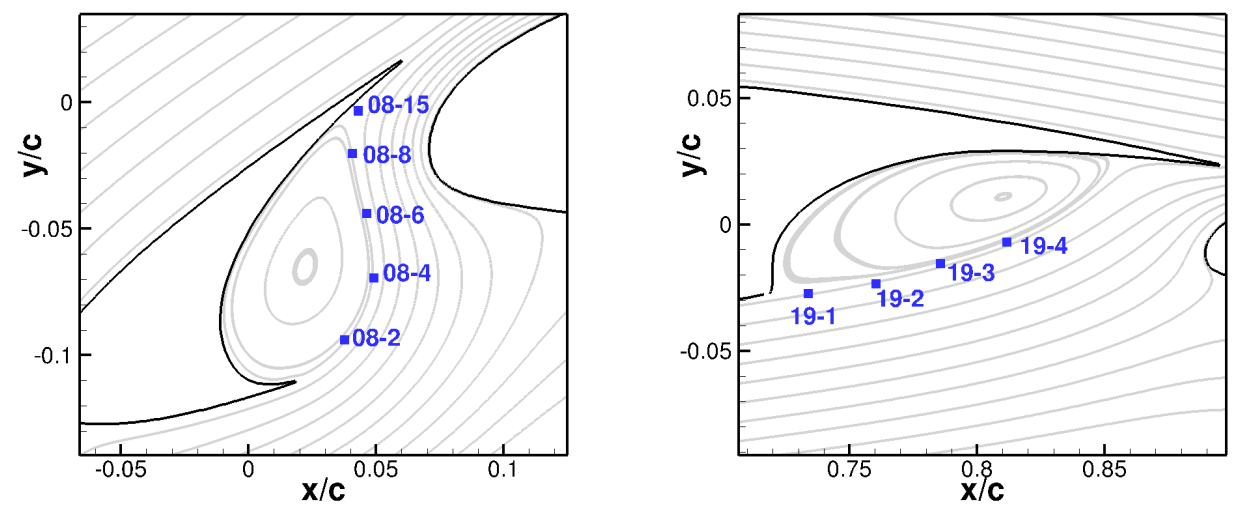

Fig. 19 Extraction probes retained for the spectral analysis and comparison against unsteady LDV measurements.
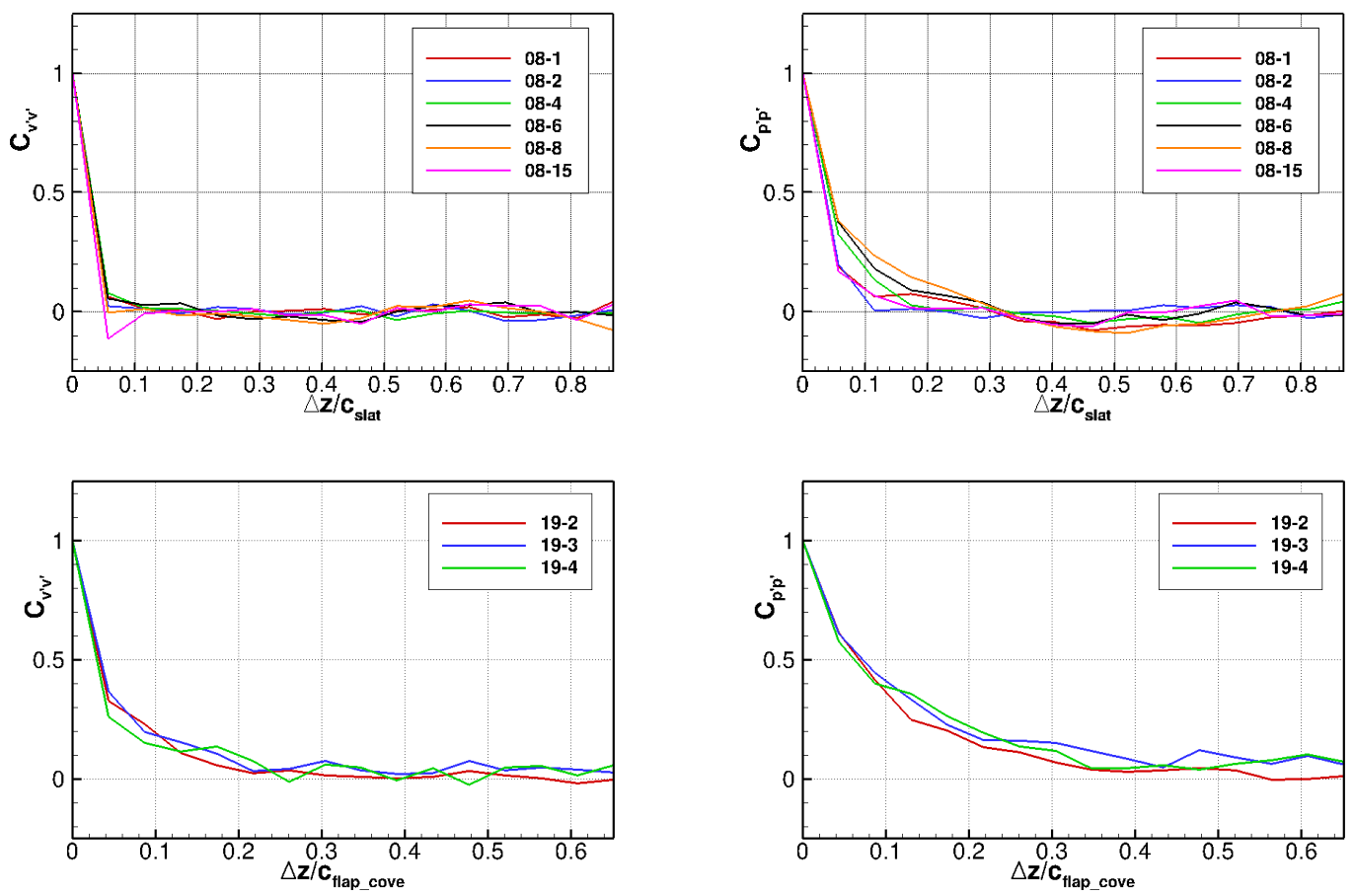

Fig. 20 Two-point spanwise correlation coefficients of vertical velocity (left) and pressure (right) fluctuations. Top: slat cove; bottom: flap cove. See Figure 19 for detailed probes locations. 

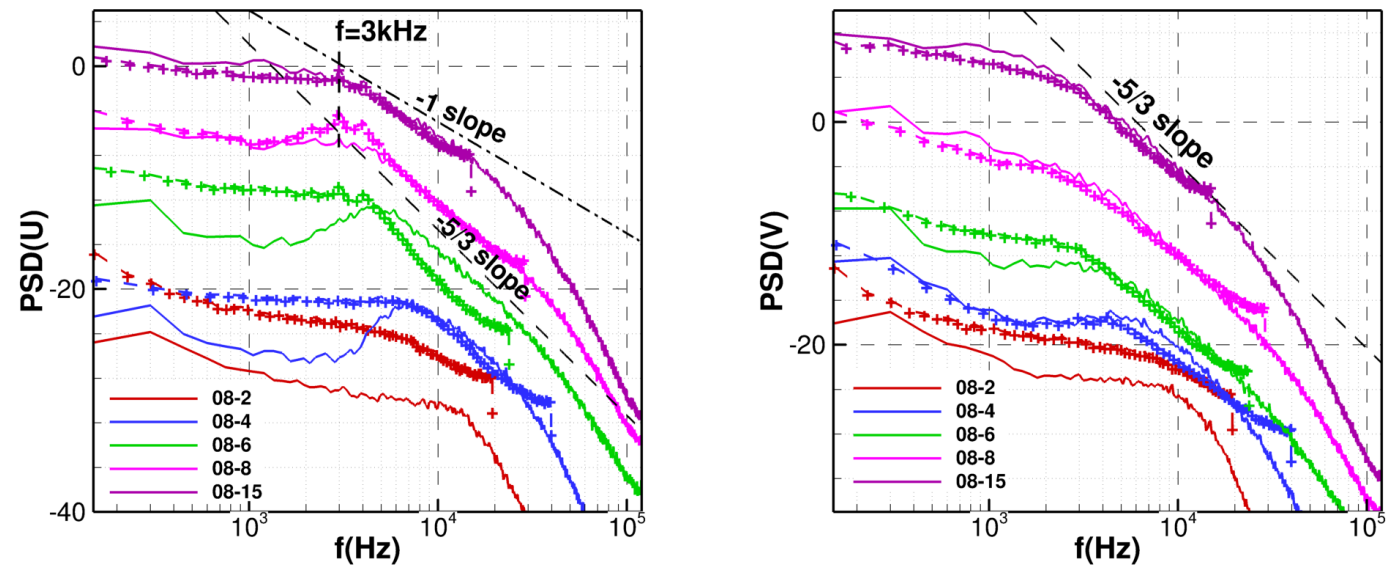

Fig. 21 Power spectral densities of velocity (in $\left.\mathbf{d B}, U_{r e f}=1 \mathrm{~m} / \mathrm{s}\right)$, computed at probes 08-2, 08-4 $(+5 \mathrm{~dB})$, 08-6 $(+10 \mathrm{~dB}), 08-8(+15 \mathrm{~dB})$ and $08-15(+20 \mathrm{~dB})$ of the slat shear layer (see Figure 19 for detailed locations). Lines: LES computation; symbols: unsteady LDV measurements.
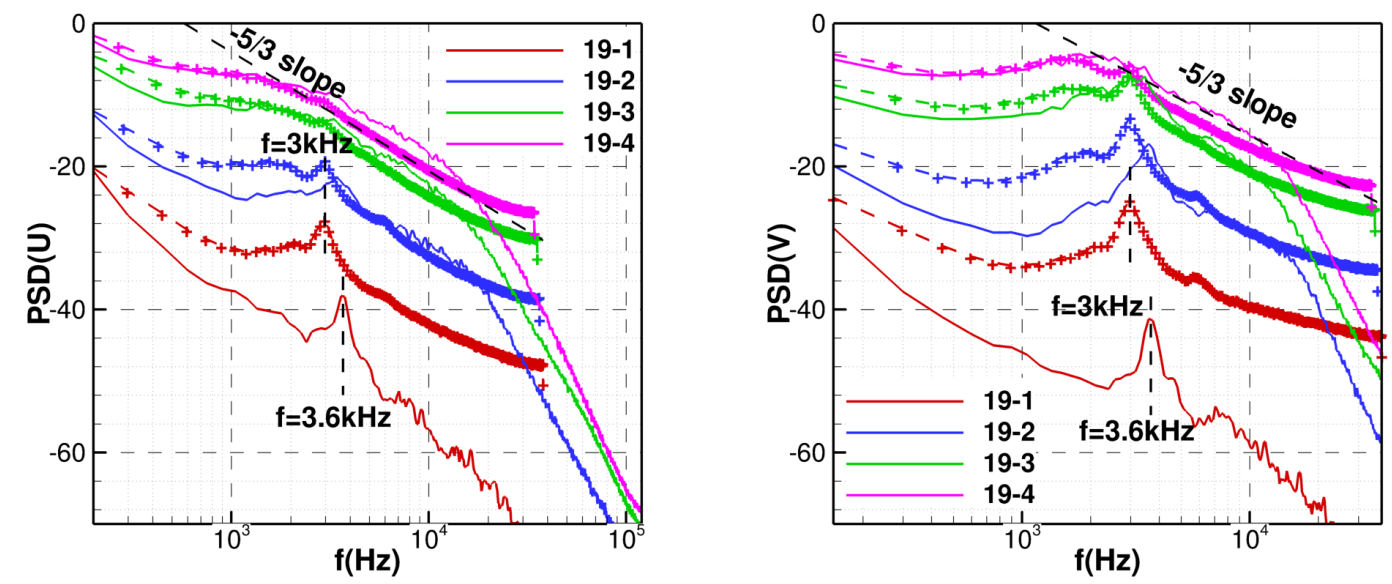

Fig. 22 Power spectral densities of velocity (in $\left.\mathbf{d B}, U_{r e f}=1 \mathrm{~m} / \mathrm{s}\right)$, computed at probes 19-1, 19-2 $(+5 \mathrm{~dB}), 19-3$ $(+10 \mathrm{~dB})$ and 19-4 (+15 dB) of the flap shear layer (see Figure 19 for detailed locations). Lines: LES computation; symbols: unsteady LDV measurements. 

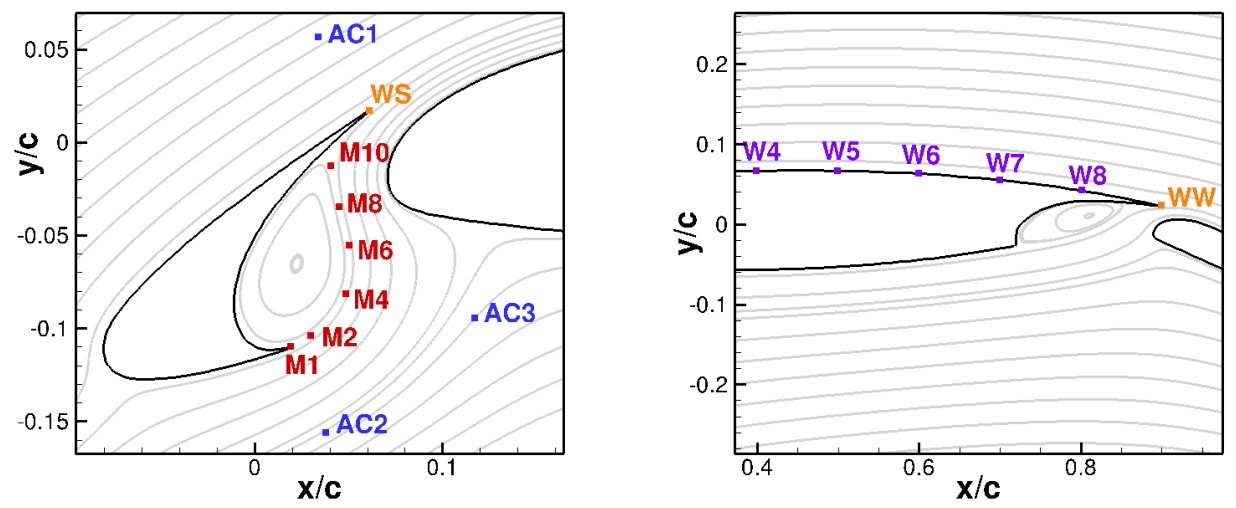

Fig. 23 Additional numerical extraction probes used for the spectral analysis.

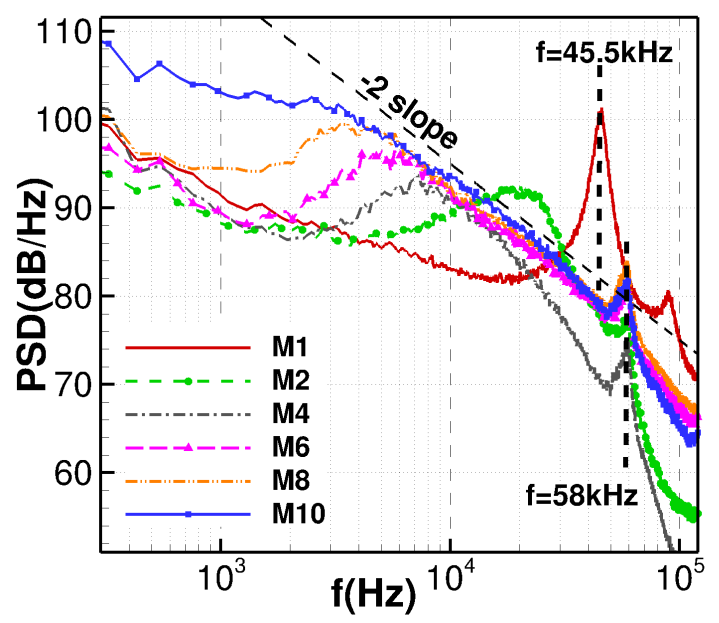

Fig. 24 Pressure spectra (in dB, $p_{\text {ref }}=2.10^{5} \mathrm{~Pa}$ ) computed at several probes located along the main shear layer in the slat cove (see Figure 23 for details).

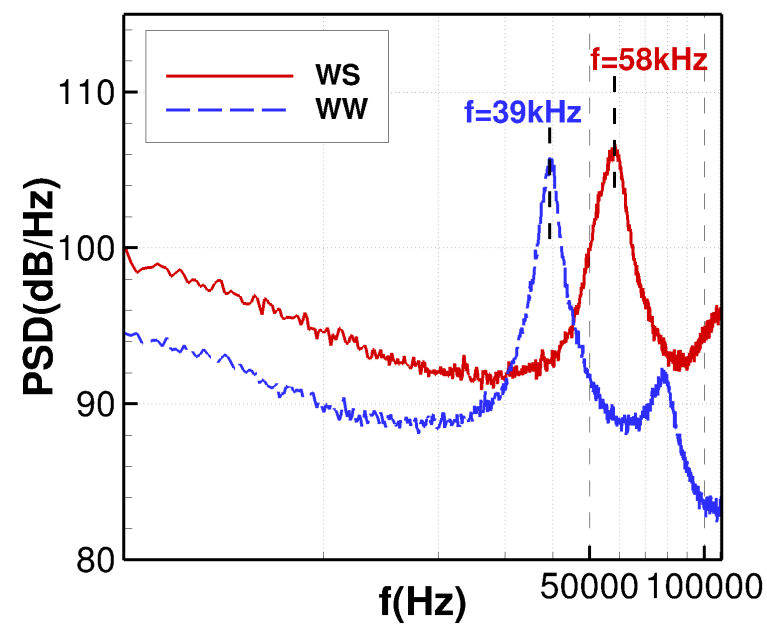

Fig. 25 Pressure spectra (in dB, $p_{\text {ref }}=2.10^{5} \mathrm{~Pa}$ ) computed at two probes located respectively in the wake of the slat trailing edge and in the wake of the main wing trailing edge (see Figure 23 for details). 


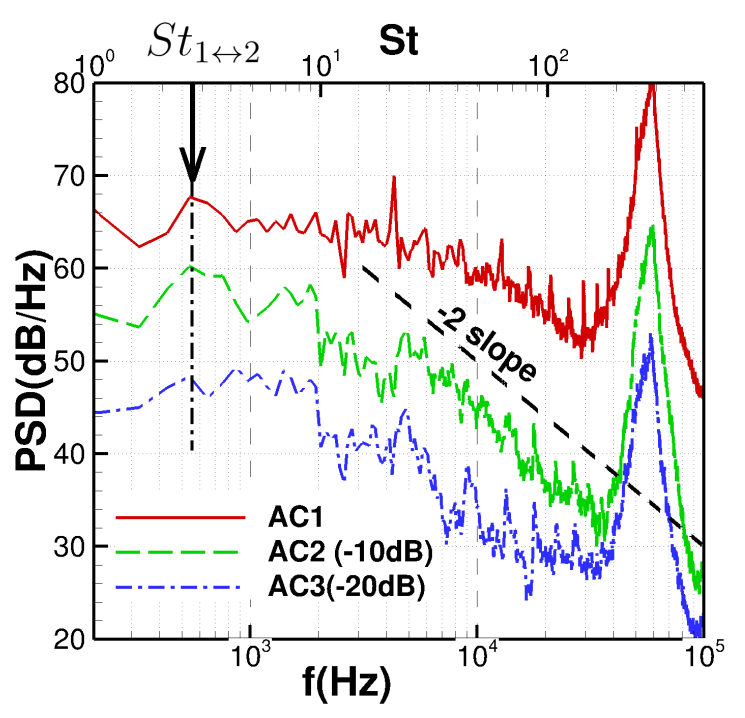

Fig. 26 Pressure spectra (in $\mathrm{dB}, p_{\text {ref }}=2.10^{5} \mathrm{~Pa}$ ) computed at three probes located in free field around the slat (see Figure 23 for details).

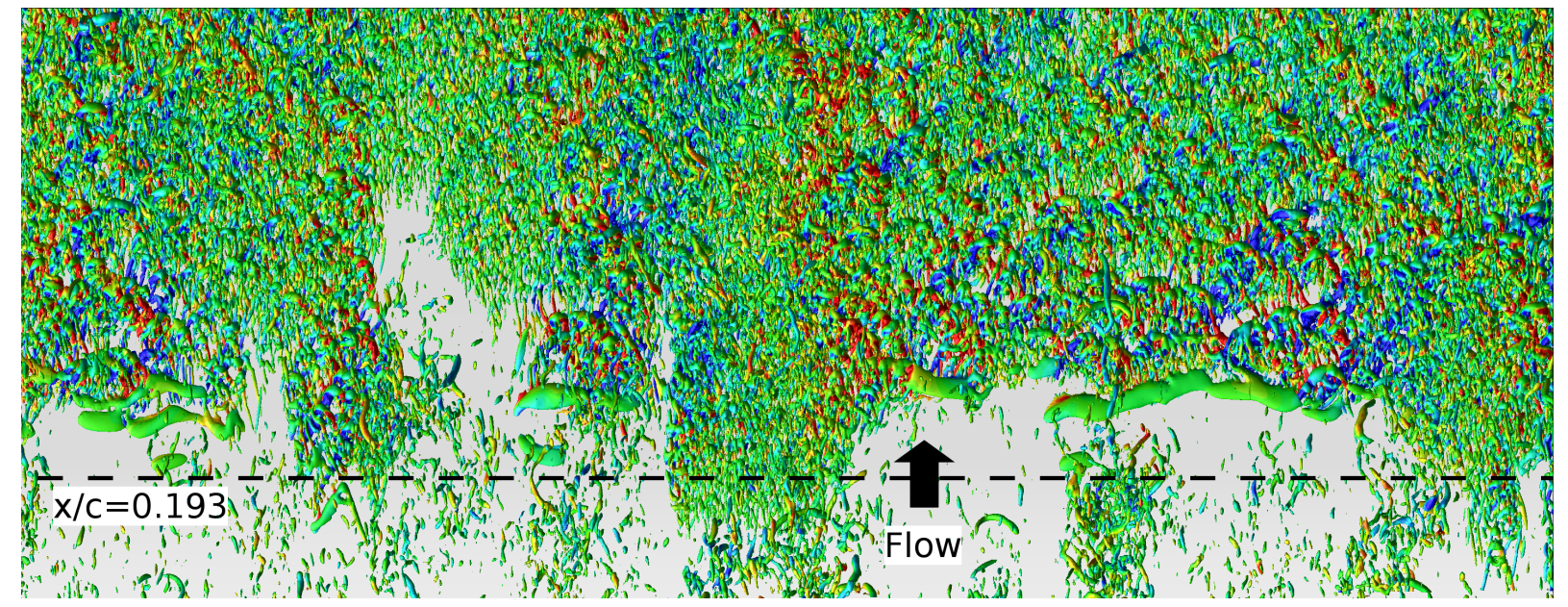

Fig. 27 Instantaneous 3D view of the boundary layer transition (iso-surface of the $Q$-criterion colored by the spanwise velocity). Top view of the suction side near $x / c=0.2\left(Q^{*}=\mathbf{5 0 0 0 0}\right)$. 

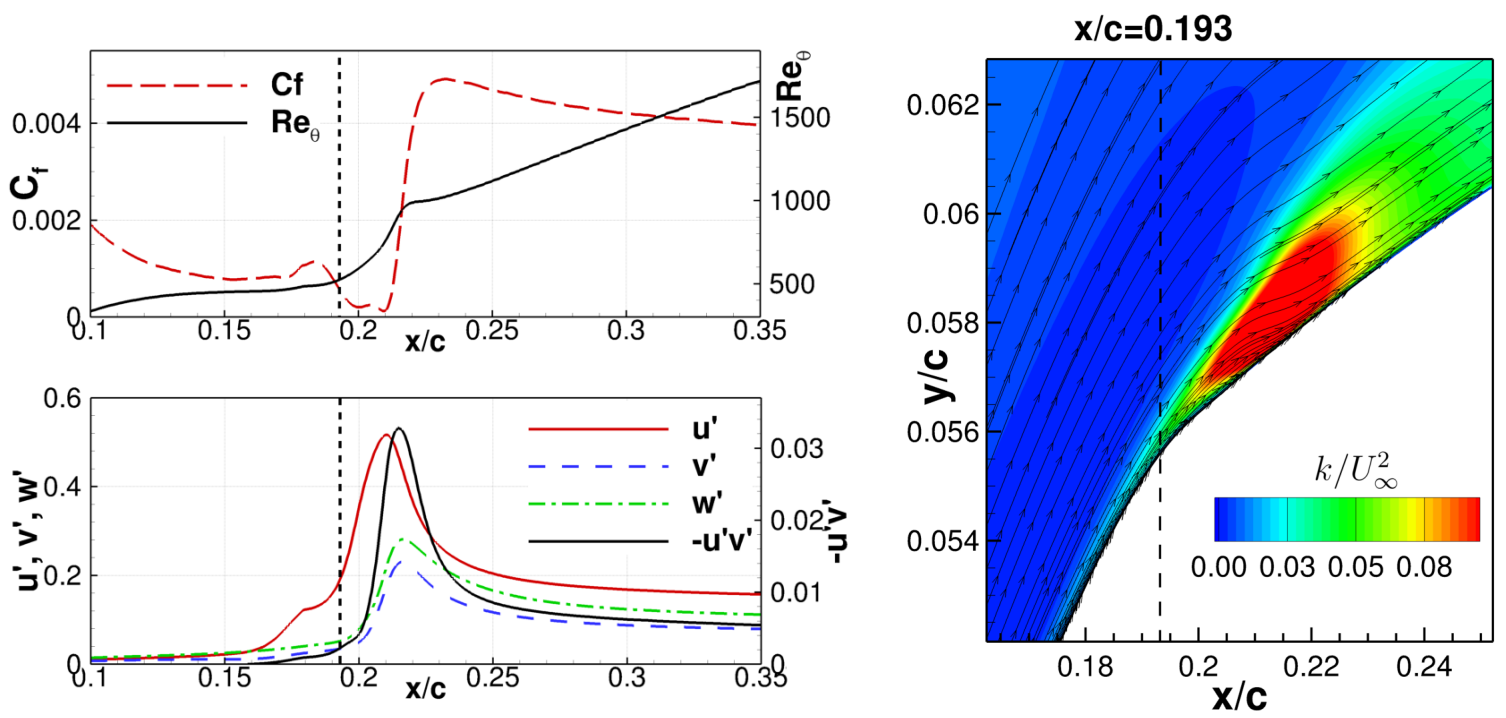

Fig. 28 Mean turbulence quantities in the transition area on the main wing's suction side.
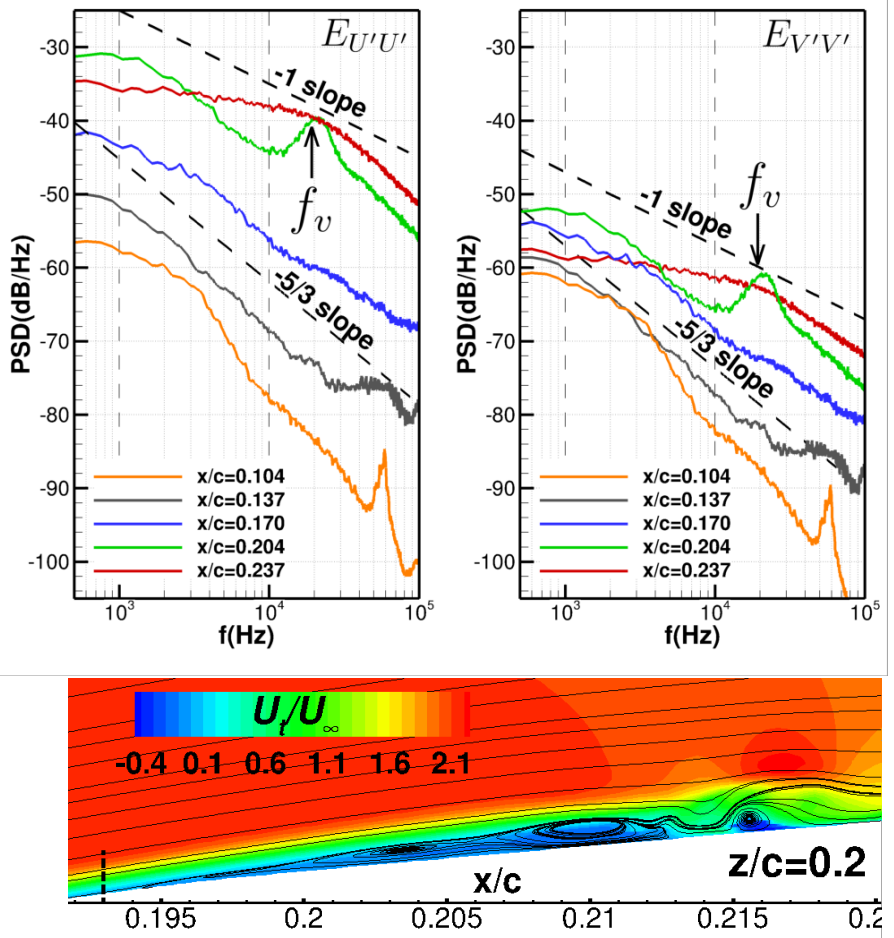

Fig. 29 Top: near-wall velocity spectra. Bottom: instantaneous tangential velocity contours near the transition location and flow streamlines $(\mathrm{z} / \mathrm{c}=0.2$ plane $)$. 


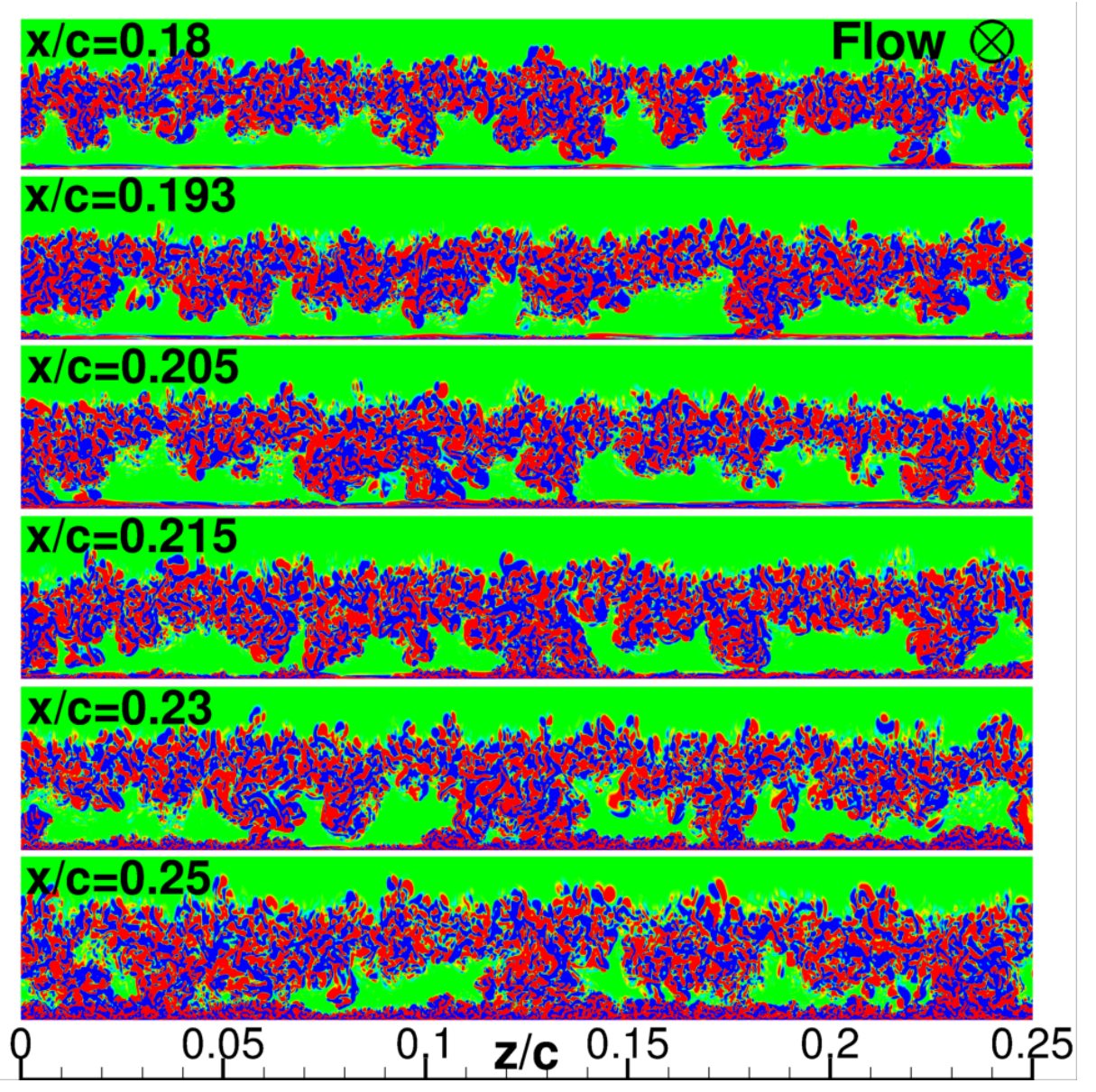

Fig. 30 Streamwise vorticity contours at several streamwise stations in the main wing transition area $\left(\omega_{x} c / U_{\infty} \in\right.$ $[-20 ; 20])$.

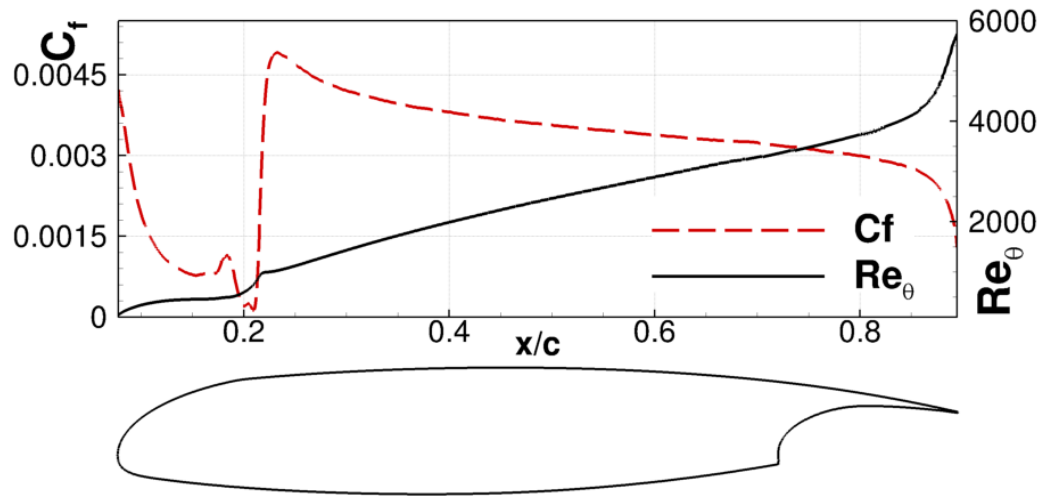

Fig. 31 Mean skin friction coefficient and $R e_{\theta}$ on the main wing suction side. 

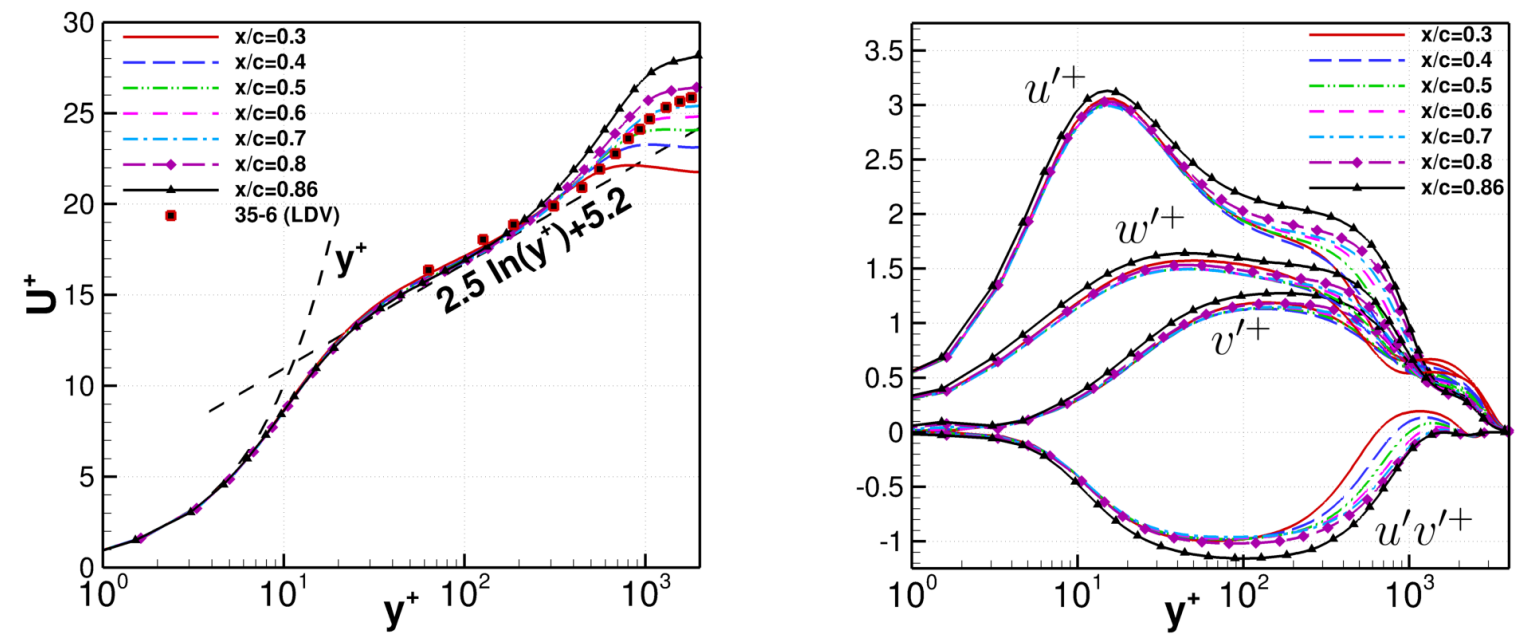

Fig. 32 Mean tangential velocity profiles (left) and resolved Reynolds stresses (right), in wall units, at different streamwise stations on the suction side of the main wing element.

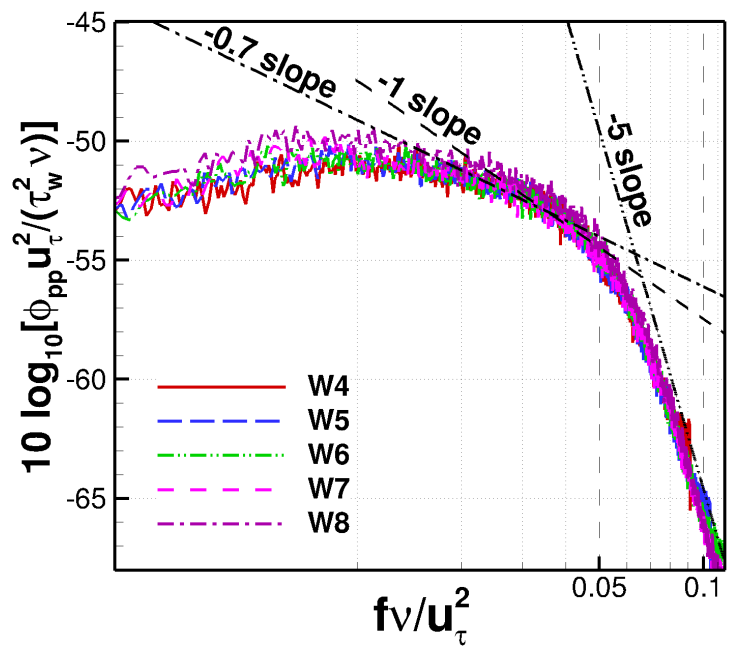

Fig. 33 Wall-pressure spectra computed at several points located on the suction side of the main wing element (see Figure 23 for details). 